\title{
LA PRESUNCIÓN DE HECHO COMO FIGURA JURÍDICA EN EL DERECHO PROCESAL CIVIL ALEMÁN*
}

\author{
The presumption of fact as a legal figure in German civil procedure law
}

Carlos Correa Robles**

Resumen: Dentro del marco de discusión referido al establecimiento de un sistema de libre valoración de la prueba en el proceso civil chileno, se efectúa el análisis de dos instituciones íntimamente relacionadas con el tema objeto del trabajo, como lo son las presunciones legales (revocables e irrevocables) y la llamada prueba prima facie. Posteriormente se efectúa un estudio pormenorizado de las presunciones de hecho, analizando la discusión sobre su naturaleza jurídica, así como la exposición de los casos de aplicación reconocidos por la jurisprudencia. Objetivo del trabajo es formular una teoría de las presunciones de hecho en el derecho procesal que logre superar las objeciones planteadas por la doctrina para su reconocimiento y aplicación práctica.

Palabras clave: presunción - prueba - carga de la prueba - valoración de la prueba.

Abstract: Considering the general framework of establishing a system of free appraisal of evidence in the Chilean procedure law, two institutions that are intimately related to the object of this work are presented, these are the legal presumption (revocable and irrevocable) and the so called prima facie evidence. Later on, a detailed study of the presumptions of fact is done, analyzing the discussion about its juridical nature, and also an exhibition of the cases where it is applied by the jurisprudence. Objective of this work is to formulate a theory of the presumptions of fact in the procedural law, which is able to overcome the objections made by the specialized literature for its recognition and practical application.

Keywords: presumption - evidence - appraisal of evidence - burden of proof.

"Nirgends herrscht eine solche Sprachverwilderung und Begriffsverwirrung wie in der Lehre von den Vermutungen"

Leo Rosenberg ${ }^{1}$

\footnotetext{
* El presente trabajo corresponde a una traducción del original bajo el título de Die tatsächliche Vermutung als Rechtsfigur des zivilprozessualen Beweisrechts, trabajo presentado en julio de 2013 como tesis para optar al grado académico Magister Legum (LL.M.) en la Universidad Libre de Berlin. Agradezco al profesor Dr. Martin Schwab, por la dirección de esta investigación, y a Mauricio Reyes, por sus correcciones y valiosos comentarios.

** Abogado, LL.M. Universidad Libre de Berlin, estudiante de Doctorado, Universidad Libre de Berlin. Correo electrónico: ccorrea81@gmail.com

${ }^{1}$ En ningún lugar reina tal confusión lingüistica y de conceptos como en la doctrina de las presunciones. ROSENBERG (1965), p. 199.
}

Este artículo fue recibido el 4 de abril de 2014, siendo aprobada su publicación el 22 de mayo de 2014. 


\section{Introducción}

El estado actual de la discusión en la doctrina y jurisprudencia alemana sobre la presunción de hecho como figura jurídica en el derecho procesal civil no hace sino confirmar la afirmación sostenida por Rosenberg hace más de 50 años.

En casos difíciles, no resulta extraño que la actividad probatoria, debido a la complejidad que genera, no pueda ser llevada a cabo mediante medios de prueba tradicionalmente denominados como directos. En muchos de estos supuestos han adoptado los tribunales, por medio del empleo de la expresión "presunción de hecho", una serie de decisiones de distinta naturaleza cuyo objetivo final es facilitar la acreditación de hechos complejos de probar, ${ }^{2}$ posibilitando en definitiva el arribo a una decisión justa. El empleo de las presunciones de hecho (llamadas también presunciones judiciales) por parte de la jurisprudencia se suele dar en dos sentidos distintos: ya sea en sede de valoración de la prueba, o bien como regla de inversión de la carga objetiva de prueba.

A causa de las múltiples opiniones sobre el contenido y finalidad que cumplen las presunciones de hecho en el proceso civil, no existe en la actualidad claridad respecto de su naturaleza jurídica ni su ámbito de aplicación. ${ }^{3}$ Con razón Laumen ${ }^{4}$ ha descrito la aplicación de este instrumento como una verdadera "tabla de salvación" utilizada de manera indiscriminada por jueces.

La confusión imperante en esta materia ha llevado a los jueces a interpretar de forma errada la función sistemática que poseen las presunciones dentro del sistema, lo que ha derivado frecuentemente en una aplicación de las mismas que lesiona el ordenamiento jurídico vigente, sacrificando certeza jurídica en pos de una solución ideal. Objeto central de este trabajo es exponer y analizar de manera crítica las distintas concepciones sobre presunciones de hecho formuladas por la jurisprudencia y doctrina alemana.

Pese al innegable interés que las presunciones de hecho han suscitado en la praxis judicial, estas han sido poco tratadas por la doctrina. ${ }^{5}$ En gran parte de los manuales y tratados sobre el proceso civil alemán las presunciones de hecho han sido ignoradas ${ }^{6}$, o bien rechazadas de plano como instrumento idóneo para resolver un problema jurídico, pese al innegable rol que ellas representan en la práctica.

\footnotetext{
2 GREGER en ZÖLLER y otros (2010), \284, pár. 33.

${ }^{3}$ PRÜTTING (1983), p. 50.

${ }^{4}$ LAUMEN en BAUMGÄRTEL et al. (2009). \ 14, pár. 1.

${ }^{5}$ Ibid.

6 Entre otros: LÜKe (2011); SChWAB (2012); JAUERnig y HeSS (2011); GrunSKy (2008); POHLMANN (2011).

7 Prütting (2013), \292, pár. 27.
} 
El presente trabajo parte de una definición de presunción de hecho entendida como una deducción lógica de máximas de la experiencia, las cuales en virtud de su tipicidad, resultan adecuadas para la acreditación de hechos, y para cuya refutación se exigirá la contraprueba. Dicha definición, cuyo alcance y justificación se desprende del análisis que a continuación se efectuará, permite sortear los inconvenientes ya referidos, dotando a dicha institución de autonomía conceptual y relevancia práctica.

Para estos efectos se efectuará un análisis de las presunciones legales y de la llamada prueba prima facie $e^{8}$ (capítulos $2^{\circ}$ y $3^{\circ}$ ), delimitando su ámbito de aplicación y estableciendo sus características principales. Renunciar al tratamiento de ambas instituciones impediría comprender las distintas interpretaciones formuladas por la doctrina y la jurisprudencia respecto de las presunciones de hecho (capítulo $4^{\circ}$ ), así como elaborar las bases para su adecuado tratamiento sistemático, tema central del capítulo final del presente trabajo.

En Chile, la teoría de las presunciones en el derecho procesal civil ha sido de un modo histórico - sin perjuicio de significativas contribuciones recientesescasamente tratada. La regulación de la prueba, contenida en el Código de Procedimiento Civil de 1902, al establecer un sistema de prueba legal o tasada ha impedido el desarrollo de una institución que en Alemania se ha desarrollado al alero de la libre valoración de la prueba, regla establecida en el $\ 286$ de la Ordenanza Procesal Civil de 1879. El desarrollo de las presunciones en el derecho alemán no tiene sin embargo su origen en dicha disposición, por el contrario, los fundamentos de la regulación hoy existente en la materia y de su desarrollo jurisprudencial y doctrinario se retrotraen a tiempos pretéritos, marcados por la vigencia del derecho común. La presente investigación busca ofrecer al lector el análisis de las distintas perspectivas referidas a este controvertido tema de acuerdo con el estado actual de la doctrina y la jurisprudencia y al mismo tiempo aportar a una discusión de enorme relevancia práctica.

En el contexto de la reforma al proceso civil chileno, en actual tramitación (Mensaje $\mathrm{N}^{\circ}$ 398-357 de 18 de mayo de 2009, boletín $\mathrm{N}^{\circ} 6567-07$ ) y el consecuente reemplazo del sistema actual de prueba legal por uno de libre valoración, el presente trabajo ofrece nuevas perspectivas de desarrollo científico en un área del Derecho que en nuestro país ha sido históricamente influenciada por autores clásicos italianos y rioplatenses.

El desarrollo alcanzado por el derecho alemán ha tenido gran influencia desde mediados del siglo pasado en el desarrollo del derecho penal chileno, y de manera reciente, tras la reforma a la justicia criminal, en el derecho procesal penal. Su recepción por parte de la doctrina civil, tanto en sede material como procesal es una tarea aún pendiente que sin duda permitirá enriquecer la discusión, aportando

\footnotetext{
${ }^{8}$ La traducción corresponde al original Anscheinsbeweis indistintamente conocido como prima facie Beweis. El concepto ha sido traducido también como "prueba por presunción". Debido a la imprecisión que genera dicha traducción, emplearemos únicamente el término prueba prima facie.
} 
Correa - La presunción de hecho como figura jurídica en el derecho procesal civil alemán

nuevas perspectivas en áreas del derecho que requieren urgentemente de nuevos desarrollos tanto legislativos como dogmáticos.

Al finalizar el presente trabajo, esperamos entregar una respuesta a la pregunta que la literatura alemana sobre las presunciones de hecho ha formulado: ¿es posible formular una teoría consistente respecto de las presunciones de hecho o bien, en coincidencia con lo sostenido por gran parte de la literatura, están todos los intentos destinados al fracaso?

\section{Las presunciones legales}

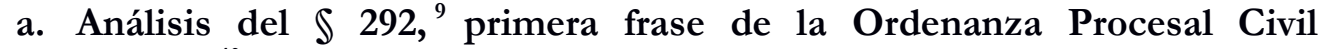 alemana $^{10}$}

Presunciones legales son normas en las cuales el legislador bajo la concurrencia de determinados elementos de hecho (presupuesto de la presunción) establece sin más la concurrencia de una determinada consecuencia jurídica (presunción). ${ }^{11}$

En el \292 la primera frase comprende dos hipótesis de presunciones legales: las llamadas presunciones legales revocables, también llamadas presunciones iuris tantum o relativas ( $\mathbb{2} 292$, primera oración) y las presunciones legales irrevocables, llamadas también presunciones iuris et de iure o absolutas $(\mathbb{2} 292$, segunda oración). El tenor literal de dicha disposición establece que las presunciones legales son esencialmente revocables (praesumtio iuris tantum). ${ }^{12} \mathrm{La}$ procedencia de presunciones legales irrevocables (praesumtio iuris et de iure) se establece entonces como excepcional, limitada a los casos en los que la ley en forma expresa así lo dispone. ${ }^{13}$

Resulta irrelevante para la determinación de una presunción legal revocable el empleo de la expresión "presunción" por parte del legislador. Por el contrario, respecto de las presunciones absolutas, se discute si la irrevocabilidad debe formularse expresamente en la ley ${ }^{14}$ o si su irrevocabilidad se desprende del tenor

\footnotetext{
${ }^{9}$ Presunciones legales. Cuando a efectos de acreditar la existencia de un hecho, establezca la ley una presunción, será admisible la prueba de lo contrario siempre y cuando la ley no indique lo contrario. (...)

${ }^{10}$ Todos los $\iint \sin$ indicación en contrario corresponden a la Ordenanza Procesal Civil alemana (ZPO).

11 PRÜTTING (1983), p. 48.

12 LEIPOLD en STEIN y JONAS (2008) \ 292, pár. 1; ASSMANN en WiECZOREK y SCHÜTZE (2012), \ 292, pár. 9; LAUMEN en PRÜTTING y GEHRLEIN (2011), \292, pár. 2; SAENGER (2013), \ 292, pár. 1; MK, PRÜTTING (2013), \292, pár. 1.

${ }^{13}$ SJK, LEIPOLD (2008), \292, pár. 1; WSK, ASSMANN (2012), \292, pár. 5; Hk-ZPO, SAEnGER (2013), \292, pár. 1; HEINRICH (1996), p. 99.

14 WSK, ASSMANN (2012), \292, pár. 3.
} 
literal de la disposición, aun cuando el legislador no haya señalado expresamente dicha cualidad. ${ }^{15}$

Ambos tipos de presunciones legales presentan estructuras propias, así como diferentes ámbitos de aplicación.

\section{b. Las presunciones legales revocables (también llamadas presunciones iuris tantum o relativas)}

La estructura de las presunciones legales revocables presenta una naturaleza dual en cuanto estas se componen por un lado de un punto de partida ajeno a la norma (llamado presupuesto base de la presunción) y de la consecuencia jurídica cuya concurrencia es presumida (presunción), que no requiere de prueba. ${ }^{16}$

Ejemplos de presunciones iuris tantum se encuentran especialmente en el ámbito del derecho civil sustantivo, por ejemplo en los $\iint 443$ inc. $2^{\circ}, 476,558 \mathrm{~d}$ inc. $3^{\circ}, 641 \mathrm{a}$ inc. $1^{\circ}$ cuarto enunciado e inc. $4^{\circ}$, segundo enunciado, $891,921,938$, 1006 inc. $1^{\circ}$ primero, y segundo enunciado, 1117 inc. $3^{\circ}, 1154$ inc. $1^{\circ}, 1253$ inc. $2^{\circ}$, 1362,1377 inc. $1^{\circ}$ y $3^{\circ}, 1600$ d inc. $2^{\circ}, 1610$ a, 1964 inc. $2^{\circ}, 2009,2255$, segundo enunciado y 2365 todos del Código Civil alemán (BGB), ${ }^{17}$ así como en leyes especiales. ${ }^{18}$

En relación con el contenido de las presunciones iuris tantum, debemos distinguir entre presunciones legales de hecho ${ }^{19}$ y presunciones legales de derecho. $^{20}$

\section{i. Presunciones legales de hecho}

Rosenberg ha definido las presunciones legales de hecho (también conocidas como "presunciones verdaderas") como preceptos jurídicos que permiten deducir la existencia de un elemento propio de una disposición legal, por medio de un hecho ajeno a esta. ${ }^{21}$

\footnotetext{
15 SJK , LEIPOLD (2008), \292, pár. 5.

${ }^{16}$ Rosenberg, SCHWAB, GOTTWARD (2010), \ 112, pár. 32; JAUERNig y Hess (2011) \50, pár. 26; HolZhammer (1986), p. 205; SJK, LeIPOLD (2008), \292, pár. 9, ss.; WSK, ASSMANN (2012), \ 292, pár. 3; LÜKE (2011), pár. 266; MUSIELAK (2010), pp. 562, 565.

17 SJK, LEIPOLD (2008), § 292, pár. 2, s.

${ }^{18}$ Para más ejemplos sobre presunciones legales revocables, así como sobre casos discutidos, vid. SJK, LEIPOLD (2008), \292, pár. 2 y s.

${ }^{19}$ Cabe señalar que se ha empleado la expresión presunciones legales de hecho para diferenciarlas de las presunciones simplemente de hecho, las cuales se analizarán posteriormente.

${ }^{20}$ LÜKE (2011), pár. 266; PGK, LAUMEN (2011), \292, pár. 3; MK, PRÜTTING (2013), 』292, pár. 3; HEINRICH (1996), p. 98.

21 Rosenberg, SchWAB, GOTTWARd (2010), \ 112, pár. 33; en el mismo sentido vid.: BAUMgÄrTEL (1990) p. 44; PGK, LAUMEN (2011), \292, pár. 3; Hk-ZPO, SAENGER (2013), \292, pár. 2.
} 
El denominado presupuesto base de la presunción corresponde a un elemento o supuesto de hecho, ajeno al tipo cuya existencia o inexistencia se busca probar. Dicho presupuesto base tiene como particularidad pertenecer al tipo de existencia de un derecho, o de su extinción ${ }^{22}$ siendo a la vez ajeno en cuanto a su contenido material a este. ${ }^{23}$ Ejemplos clásicos de presunción de hecho son la presunción de extinción de la hipoteca por medio de la entrega de la carta de hipoteca, producto de la posesión por parte del acreedor que está de acuerdo al $\int 1117$ inc. $3^{\circ} \mathrm{BGB}$, o la posesión de la cosa prendada por parte del acreedor, que permite acreditar el tipo de extinción de la prenda por medio de su entrega, de acuerdo con el $\$ 1253$ inc. $2^{\circ}$ BGB $^{24}$. Otros ejemplos se encuentran en los $\$ \int 938$, 1377 inc. $1^{\circ}$, inc. 3,1600 b, 2009 BGB, así como en los $\iint 363$, 685 inc. $2^{\circ}, 1213$ inc. $2^{\circ}, 1360 \mathrm{~b}, 1600 \mathrm{c}, 1600 \mathrm{~d}$ inc. $2^{\circ}, 1620,1625,2270$ inc. $2^{\circ} \mathrm{BGB}$, los cuales no contienen una indicación expresa del término presunción. ${ }^{25}$

La carga de suministración de la prueba del presupuesto base de la presunción -por aplicación de las reglas generales de la carga de la pruebacorresponde a quien alega para sí las consecuencias jurídicas de la presunción. ${ }^{26}$

\section{ii. Presunciones de derecho}

Presunciones de derecho están dirigidas a acreditar la existencia o inexistencia de un derecho o una relación jurídica. ${ }^{27}$ En contraposición a las presunciones de hecho, las presunciones de derecho no se encuentran comprendidas directamente en el tenor literal del $\$ 292 .^{28}$ Pese a ello, existe unanimidad en que dicho parágrafo resulta a su respecto igualmente aplicable..$^{29}$

Elementos de las presunciones de derecho no son hechos, sino directamente un derecho o una relación jurídica. ${ }^{30}$ Como ejemplos se suelen mencionar entre otros la presunción del derecho de propiedad derivada de la posesión, consagrada en el $\int 1006$ inc. $1^{\circ}$, primer enunciado BGB, ${ }^{31}$ la presunción de existencia del derecho inscrito a partir de su inscripción en el registro de propiedad ( $\left(891\right.$ inc. $\left.1^{\circ} \mathrm{BGB}\right)$, o

\footnotetext{
22 MusielaK (2012a), p. 993; PGK, LAUMEN (2011), 』292, pár. 3.

23 ROSENBERG (1965), p. 203.

${ }^{24}$ RosenberG, SCHWAB, GOTTWARD (2010), 』112, pár. 33; WSK, ASSMANN (2012), 』 292, pár. 7; Huber, en Musielak (2012a), p. 824; LAUMEN en BAUMGÄrTEL et al. (2009), \14, pár. 6.

${ }^{25}$ Rosenberg, Schwab, GotTward (2010), 』112, pár. 33; Musielak, Huber (2012a), p. 993; MusielaK (2012b), pár. 479; PGK, LAUMEN (2011), \292, pár. 3; MK, PRÜTTinG (2013), \292, pár. 12.

26 PRÜTTING (1983), p. 337.

27 Rosenberg (1965), p. 225; Rosenberg, Schwab, GotTward (2010), \ 112, pár. 35; cfr. MusielaK, Huber (2012a), p. 993; Hk-ZPO, SAENGER (2013), \292, pár. 3.

28 WSK , ASSMANN (2012), \292, pár. 8; Hk-ZPO, SAENGER (2013), 』292, pár. 3.

${ }^{29}$ WSK, ASSMANN (2012), \ 292, pár. 8.

30 Rosenberg, Schwab, GotTward (2010), \112, pár. 35; Musielak, Huber (2012a), p. 993.

31 RosenberG, SCHWAB, GotTWARD (2010), \112, pár. 35; WSK, ASSMANN (2012), \292, pár. 8; LÜKE (2011), pár. 266; PGK, LAUMEN (2011), \ 292, pár. 3; Hk-ZPO, SAENGER (2013), \ 292, pár. 2.
} 
respectivamente su inexistencia por medio de su eliminación del registro $(§ 891$ inc. $2^{\circ}$ BGB). Otras hipótesis se encuentran en $\operatorname{los}^{32} \iint 921,1138,1155,1360 \mathrm{~b}, 1362$, 1380 inc. $1^{\circ}$, segundo enunciado, 1620,1964 inc. $2^{\circ}, 2255$, segundo enunciado, $y$ $2365 \mathrm{BGB}^{33}$

Presunciones legales de hecho y de derecho se encuentran en la misma relación que elementos de hecho y de derecho como componentes de una norma ${ }^{34}$ siendo ambas categorías esencialmente idénticas en cuanto a su estructura y efectos, se encuentran reguladas por el $\int 292$ primera oración y -como veremosproducen idéntico efecto sobre las reglas objetivas de carga de la prueba. ${ }^{35}$

\section{c. Efectos de las presunciones legales revocables}

Quien demanda a su favor la existencia de un hecho o derecho legalmente presumido debe primero invocar el presupuesto base de la presunción y en cuanto no sea su existencia incontrovertida o corresponda a un hecho público, debe el interesado acreditarlo plenamente. ${ }^{36} \mathrm{~A}$ este respecto rigen sin contrapeso las reglas generales de distribución y carga de la suministración de la prueba. ${ }^{37}$

Solo cuando quien debe probar el presupuesto de la presunción y la ha acreditado plenamente, entra en consideración el segundo elemento: la presunción. Los efectos que esta genera se efectúan por medio de un desplazamiento del objeto a probar. ${ }^{38}$ De acuerdo con Holzhammer (1986), las reglas legales sobre presunciones alivian considerablemente la actividad probatoria, en cuanto el objeto a probar se traslada, como así lo demuestran los ejemplos ya mencionados, desde la acreditación de complejos presupuestos legales a hechos cuya acreditación resulta más sencilla. ${ }^{39}$

\section{d. Falta de necesidad de prueba de los hechos o derechos presumidos}

Actualmente no existe controversia ${ }^{40}$ sobre si respecto del derecho o hecho presumido existe igualmente un deber de acreditación; la parte beneficiada con el efecto de la presunción, acreditado sea el presupuesto de esta última, no debe

\footnotetext{
${ }^{32}$ Fuera del Derecho Civil cumplen las presunciones legales un papel importante en el derecho de carteles. Sobre el tema y múltiples ejemplos en el área del derecho radiofónico, de responsabilidad medioambiental, de técnicas genéticas y derecho de insolvencia, vid. MK, PRÜTTING (2013), \292, pár. 15, ss.

${ }^{33}$ MUSIELAK (2012a), p. 993; (2012b), pár. 480; PGK, LAUMEN (2011), \ 292, pár. 3; Hk-ZPO, SAENGER (2013), \292, pár. 2; MK, PRÜTTING (2013), \292, pár. 12.

34 MusielaK (2012b), pár. 480; MK, PRÜTTING (2013), \292, pár. 5.

35 Prütting (1983), p. 48; WSK, AsSMANN (2012), \292, pár. 6; MK, PRÜtTing (2013), \292, pár. 11.

${ }^{36}$ SJK, Leipold (2008), \292, pár. 10, ss.; MusielaK (2010), p. 565, ss.; MK, PRÜTTing (2013), 』

292, pár. 20; BAUMBACH (2012), pár. 9.

${ }^{37}$ SJK, LEIPOLD (2008), \292, pár. 13; MK, PRÜTTING (2013), 』 292, pár. 20.

${ }^{38}$ Rosenberg (1965), p. 217; SJK, LeIPOLD (2008), \292, pár. 9; PGK, LAUMEN (2011), \292, pár. 4.

${ }^{39}$ HolZHAMmer (1986), p. 205.

40 MK, PRÜTTING (2013), \292, pár. 21.
} 
siquiera invocar la aplicación de la presunción ni tampoco estará sujeta a una comprobación ulterior de los efectos de esta, pues el juez la conoce y en consecuencia no debe sino aplicarla. ${ }^{41}$ En otras palabras, cuando los presupuestos de la presunción se encuentran acreditados, se producen sus efectos de oficio (tal como sucede por ejemplo respecto de los hechos públicos y notorios) sin necesidad de producción de prueba adicional. ${ }^{42}$ La presunción exime entonces a la parte beneficiada de la carga de la prueba, y de la necesidad de invocar la norma a su favor. ${ }^{43}$

Atendido que las presunciones legales permiten acreditar elementos típicos ajenos a estas, ${ }^{44}$ se encuentra el $\int 292$ en sintonía con otros instrumentos del proceso civil, que eliminan la necesidad de prueba respecto de hechos invocados, por ejemplo los hechos no controvertidos $\left(\$ 138\right.$ inc. $\left.3^{\circ}\right)$, la confesión $(\$ 288)$ y los hechos públicos (\$291). ${ }^{45}$

Frente a la presencia de presunciones legales y a diferencia de las presunciones de hecho no tiene lugar una valoración de la prueba por parte del tribunal, sino por el contrario, su efecto se reduce a la aplicación directa de una disposición legal. ${ }^{46}$

\section{e. La refutación del efecto de la presunción legal}

\section{i. La refutación del efecto de los presupuestos base de la presunción}

La presunción legal puede ser refutada por dos vías; por medio de la refutación de los presupuestos base de esta, o bien por la refutación de la presunción misma. ${ }^{47}$ Ambas posibilidades se diferencian entre sí en relación con sus requisitos y características.

La presunción puede refutarse en primer lugar, de acuerdo con las reglas generales, por medio de la contraprueba dirigida a desvirtuar sus presupuestos base. ${ }^{48}$ Cuando dicha contraprueba es exitosa, cesan los efectos de la presunción así como sus consecuencias. De tal modo, descartada sea la aplicación de una presunción, la

\footnotetext{
${ }^{41}$ BGH NJW (2010), 363; a favor: MusielaK (1975), S. 55. Contra: MusielaK (2010), p. 565; MK, PRÜTTING (2013), \292, pár. 21; WSK, ASSMANN (2012), \292, pár. 28, s.

${ }^{42}$ Rosenberg, SCHWAB, GOTTWARD (2010), \ 112, pár. 33-35; SJK, LeIPOLD (2008) \ 292, pár. 8, 14; WSK, ASSMANN (2012), \292, pár. 28, s.; PGK, LAUMEN (2011), \ 292, pár. 4; MUSIELAK (2010), p. 565; LAUMEN en BAUMGÄRTEL et al. (2009), \14, pár. 6.

43 BHG NJW (2010), 363.

${ }^{44}$ MusielaK (2010), p. 562.

${ }^{45}$ MK, PRÜTTING (2013), \292, pár. 1.

46 PGK, LAUMEN (2011), \$ 292, pár. 4.

${ }^{47}$ Hk-ZPO, SAENGER (2013), \ 292, pár. 12.

48 SJK, LEIPOLD (2008), \ 292, pár. 13; HolZhAmMeR (1986), p. 205; WSK, AssmanN (2012), \292, pár. 29; PGK, LAUMEN (2011), \ 292 pár. 5; Hk-ZPO, SAENGER (2013), \292, pár. 5; MK, PRÜTTING (2013), \292, pár. 20.
} 
parte sobre la cual recae la carga de suministración de la prueba deberá acreditar el hecho directamente con los medios de prueba usuales. ${ }^{49}$

\section{ii. Refutación de la presunción misma}

Ya que el hecho acreditado por medio de una presunción corresponde a prueba de carácter principal, ${ }^{50}$ solo puede refutarse la presunción en cuanto tal, cuando se establezca que el hecho o, respectivamente, el derecho presumido no existe. ${ }^{51}$ Para ello no bastará con acreditar la mera posibilidad de otro acontecimiento, ${ }^{52}$ sino que se exigirá a la contraparte (por el empleo de todos los medios de prueba disponibles) ${ }^{53}$ la plena prueba de lo contrario. ${ }^{54}$ Esta prueba (que no es contraprueba, sino prueba principal ${ }^{55}$ tendrá entonces por finalidad convencer plenamente al tribunal de la inexistencia del derecho o hecho objeto de la presunción. ${ }^{56}$

\section{f. Posición sistemática de las presunciones legales revocables}

Como se señaló, la parte que pretende beneficiarse de los efectos de la presunción solo deberá probar los presupuestos base de esta, ${ }^{57}$ la doctrina mayoritaria ha sostenido que las presunciones iuris tantum producen una inversión de la carga objetiva de la prueba en beneficio de la parte beneficiada por el efecto de la presunción. $^{58}$

\footnotetext{
49 PGK, LAUMEN (2011), \292, pár. 5; BAUMBACH (2012), \292, pár. 9.

${ }^{50}$ Rosenberg (1965), p. 211.

51 MusielaK (2012b), pár. 481, (2012a), p. 993; JAUERnig y HeSs (2011), \50, pár. 27; PGK, LAUMEN (2011), \292, pár. 5.

52 Rosenberg, SCHWAB, GotTwARd (2010), \112, pár. 34; SJK, Leipold (2008), \292, pár. 16; WSK, ASSMANN (2012), \ 292, pár. 30; PGK, LAUMEN (2011), \292, pár. 5; BAUMBACH (2012), 』 292, pár. 9; ZÖLLER, GREGER (2010), \292, pár. 2.

53 PGK, LAUMEN (2011), \292, pár. 5; BAUMBACH (2012), \292, pár. 8; WSK, ASSMANN (2012), \ 292, pár. 32; ZÖLLER, GREGER (2010), \292, pár. 2.

54 SJK, LEIPOLD (2008), \292, pár. 16, s.; HOLZHAMMER (1986), p. 205; WSK, ASSMANN (2012), \ 292, pár. 30, ss.; RosenBerG, SCHWAB, GOTTWARD (2010), \112, pár. 32; MusielaK (2012b), pár. 481; PGK, LAUMEN (2011), \292, pár. 5; Hk-ZPO, SAENGER (2013), \292, pár. 12; MK, PRÜTTING (2013), \ 292 pár. 20; ZÖLLER, GREGER (2010), \ 292, pár. 2; BRUNS (1979), p. 240.

${ }^{55}$ JAUERNIG y HeSS (2011), \50 pár. 27; LÜKE (2011), pár. 266; PGK, LAUMEN (2011), \292, pár. 5; WSK, ASSMANN (2012), \292, pár. 32.

${ }^{56}$ BGH NJW 02, 2101, 2102; 04, 217, 219; cfr. RosenberG, SCHWAB, GOTTWARD (2010), \112, pár. 32; WSK, ASSMANN (2012), \292, pár. 30; PGK, LAUMEN (2011), \ 292, pár. 5; Hk-ZPO, SAENGER (2013), \292, pár. 12.

${ }^{57}$ Evidentemente la existencia de una presunción legal revocable no obsta a la posibilidad de acreditar el hecho por medio de la plena prueba recaída directamente en este.

${ }^{58}$ Rosenberg (1965), pp. 216, 224; PGK, LAUMEN (2011), \ 292, pár. 4; MK, PrÜtTing (2013), 』 292, pár. 26; PRÜTTING (1983), p. 1028.
} 
Un sector minoritario de la doctrina ${ }^{59}$ sostiene, por el contrario, que las presunciones relativas no alteran las reglas objetivas de la carga de la prueba, sino que únicamente simplifican la prueba por medio del ya referido desplazamiento del objeto de la misma, ${ }^{60}$ en cuanto el interesado solo deberá invocar y probar el presupuesto de la presunción, mas no la presunción en sí.

La teoría de la simplificación de la prueba se basa en el razonamiento consistente en que en la práctica la prueba exclusiva de los presupuestos base de la presunción implicará una considerable disminución en la dificultad de la actividad probatoria, ${ }^{61}$ en cuanto reemplaza la generalmente compleja prueba del derecho o hecho presumido por la (simple) prueba del presupuesto base.

Esta sustitución del objeto de la prueba ignora sin embargo lo que realmente desean acreditar o controvertir los involucrados: el hecho o derecho objeto de la presunción.

Cuando el juez, tras la rendición de prueba, no puede tener por acreditado un hecho controvertido se encuentra imposibilitado de decidir -de conformidad a las reglas del derecho material- la existencia o inexistencia de este. Atendido que por regla general cada parte tiene la carga de la prueba respecto de los presupuestos de hecho de las normas jurídicas que a su favor invoca, ${ }^{62}$ se simula en estos casos (non liquet) un resultado probatorio negativo. ${ }^{63}$ En este sentido, las reglas de alteración de la carga de la prueba representan excepciones al ya descrito efecto general suscitado ante la presencia de un non liquet. ${ }^{64}$ Por medio de la plena prueba de los presupuestos de la presunción se genera -mediante una ficción- un resultado probatorio positivo, alterando así la carga objetiva de la prueba en perjuicio del adversario de la parte beneficiada por la presunción.

Por ello, las presunciones legales revocables constituyen preceptos jurídicos que alteran la distribución objetiva de la carga de la prueba entre las partes, ${ }^{65}$ no pudiendo ser consideradas entonces reglas de valoración de la prueba. ${ }^{66}$ Por medio de las presunciones legales no comprobará el juez la existencia de hecho o derecho alguno, ${ }^{67}$ sino simplemente lo tendrá por acreditado.

\footnotetext{
59 BAUMBACH (2012), \292, pár. 9; BRUNS (1979), p. 241; Lüke (2011), pár. 266; ZÖLLER, GREGER (2010), \292, pár. 2.

${ }^{60}$ BRUNS (1979), p. 241.

${ }^{61}$ BGH NJW 1994, 1880; 1987, 2876; cfr. LÜKE (2011), pár. 266; HOLZHAMMER (1986), p. 205.

${ }^{62}$ MusielaK (2010), pp. $561 \mathrm{ss.}$

${ }^{63}$ Ibid.

${ }^{64}$ Rosenberg, SchWab, GotTward (2010), 』114, pár. 33; ANZiger (2006), p. 41; Musielak (2010), p. 561.

65 PrÜtTiNg (1983), p. 337; MK, PrÜtTiNg (2013), 』292, pár. 26; LAUMEN en BAUMGÄRTEL et al. (2009), \14, pár. 6.

${ }^{66}$ Rosenberg, Schwab, GotTward (2010), \112, pár. 34; PrütTing (1983), p. 48; Musielak (2012a), p. 993; PGK, LAUMEN (2011), \292, pár. 4; MUSIELAK (2010), p. 561.

67 PRÜTTING (1983), p. 49.
} 
Solo cuando las presunciones legales se conciben como reglas de alteración de la carga objetiva de la prueba y no como instrumentos propios de la valoración de la prueba se comprende la ya referida estructura dual de su refutación, y en particular el requisito especial de producción de la plena prueba de lo contrario para desacreditar la presunción misma.

\section{g. Las presunciones legales irrevocables (presunciones iuris et de iure o absolutas)}

Como ya fue expuesto, el tenor literal del $\ 292$ comprende exclusivamente a las presunciones iuris tantum. ${ }^{68}$ Por el contrario, respecto de las irrevocables, en principio $^{69}$ no se acepta la procedencia de prueba en contrario, de conformidad a lo dispuesto en la ya referida disposición. ${ }^{70}$ En virtud de lo anterior, se ha señalado que este tipo de presunciones no generan efecto alguno en la carga de la prueba, ni en la valoración que se efectúa de esta, ${ }^{71}$ siendo estas exclusivamente preceptos legales que establecen la realización de determinados efectos jurídicos, ${ }^{72}$ independientemente de si dicho efecto en el caso concreto se condice o no con la realidad. $^{73}$

Pese a que comúnmente se designa a las presunciones absolutas dentro del concepto general de "presunciones" contenido en el $\ 292$, se trata más bien en estos casos de un tipo jurídico distinto, compuesto ${ }^{74}$ por una parte del presupuesto de la presunción, el cual (igual que como sucede con las presunciones iuris tantum) debe ser probado, y de la presunción misma, la cual genera sus efectos independiente -por regla general- de la existencia de contraprueba o prueba de lo contrario. $^{75}$

Ejemplos de presunciones legales irrevocables son escasos, ${ }^{76}$ siendo los casos más relevantes el contemplado en el $\int 1566$ inc. $1^{\circ} \mathrm{BGB}, \mathrm{y} \int 344$ inc. $2^{\circ}$ Código de Comercio alemán (HGB). ${ }^{77}$

\footnotetext{
${ }^{68}$ PGK, LAUMEN (2011), p. 824; WSK, ASSMANN (2012), \292, pár. 9; Hk-ZPO, SAENGER (2013), \292 pár. 3; MK, PRÜTTING (2013), \292, pár. 4.

${ }^{69}$ El Tribunal Supremo alemán ha aceptado excepcionalmente la posibilidad de revocar los efectos de la presunción contenida en el $\ 344$ inc. $2^{\circ}$ Código de Comercio alemán (HGB). Los alcances de dichas excepciones exceden el ámbito de este trabajo.

70 WSK, ASSMANN (2012), \292, pár. 34.

71 PrÜtTiNg (1983), p. 49; MK, PRÜTTING (2013), \ 292, pár. 4.

72 Musielak (2012b), pár. 481; PGK, LAumen (2011), \ 292 pár. 2; MK, PrütTing (2013), \ 292, pár. 4.

73 PGK, LAUMEN (2011), \292, pár. 2.

${ }^{74}$ SJK, LEIPOLD (2008), \292, pár. 5; MK, PRÜTTING (2013), 』 292, pár. 4.

75 Sobre la diferencia entre las presunciones absolutas y las ficciones vid. ROSENBERG (1965), p. 212, s.; WSK, ASSMANN (2012), \292, pár. 9; BAUMBACH (2012), \292, pár. 5; PRÜTTING (1983), p. 48; MK, PRÜTTING (2013), \ 292, pár. 4.

${ }^{76}$ MK, PRÜTTING (2013), \292, pár. 4; BAUMBACH (2012), \ 292, pár. 5.
} 


\section{La prueba prima facie ${ }^{78}$}

\section{a. El principio de libre valoración de la prueba en el proceso civil}

El $\int 286^{79}$ de la Ordenanza Procesal Civil alemana establece el principio de libre valoración de la prueba en el proceso civil. Este principio señala, según Musielak, que el juez en el establecimiento de hechos relevantes para el proceso civil no se encuentra sujeto a reglas de valoración legal de la prueba, que establezcan a priori el valor probatorio de determinados medios de prueba, sino que debe decidir de acuerdo a su propio convencimiento y parecer, si considera el hecho controvertido como verdadero o no verdadero. ${ }^{80}$

\section{i. Limitaciones a la libre valoración de la prueba de acuerdo con reglas legales de valoración de la prueba}

De acuerdo con lo dispuesto en el $\ 286$ inc. $2^{\circ}$ se encuentra el tribunal solo por excepción sujeto a reglas legales de valoración de la prueba, limitándose dicha excepción exclusivamente a los casos consagrados de manera expresa por el legislador. ${ }^{81}$ En estos establece este último determinadas reglas que limitan la posibilidad del juez de llegar a un convencimiento libre sobre el valor de la prueba rendida. ${ }^{82}$ Estas reglas conducen a la determinación de la verdad o bien falsedad de un hecho controvertido sin considerar la convicción personal del juez. ${ }^{83}$

Ejemplos de dichas reglas podemos encontrar en el $\int 139$ inc. $4^{\circ}$ tercer enunciado (prueba de la falsedad como único medio de prueba admisible contra el contenido de un acta); $\int 165$, segundo enunciado (valor probatorio del protocolo); $\int 314$ (valor probatorio de los hechos contenidos en la sentencia); $\int 174$ inc. $4^{\circ}$, primer enunciado (prueba de la entrega de un documento); $\int 183$ inc. $2^{\circ}$, segundo enunciado (entrega en el extranjero); \ 195 inc. $2^{\circ}$ (prueba de la entrega de abogado a abogado); $\int 415$ (valor probatorio de los documentos públicos y declaraciones); \416 (valor probatorio de los documentos privados); \416 a (valor probatorio de la impresión de un documento electrónico); \417 (valor probatorio

\footnotetext{
77 SJK, LEIPOLD (2008), \292, pár. 4; contra: WSK, AsSMANN (2012), 』 292, pár. 9; Hk-ZPO, SAENGER (2013), \292, pár. 5; BRUNS (1979), p. 241.

${ }^{78}$ Sobre la prueba prima facie en el ordenamiento jurídico austriaco vid. HolZHAMMER (1986), pp. 205, ss.

${ }^{79}$ Libre valoración de la prueba. El tribunal decidirá a partir del análisis del contenido global del litigio y del resultado de una eventual recepción de prueba si el hecho alegado es tenido o no por cierto. En la sentencia deberá el juez. exponer las razones que fundamentan su convicción.

El tribunal se encuentra sujeto a reglas de valoración legal de prueba solo en los supuestos en que la ley expresamente asi lo dispone.

80 MusielaK (2010), p. 562; (2012b), pár. 458; en similar sentido: Rosenberg, SCHWAB, GOTTWALD (2010), \113, pár. 1.

${ }^{81}$ MusielaK (2010), p. 562; Schwab (2012), pár. G 487.

82 SCHWAB (2012), pár. G 487.

83 Rosenberg, SCHWAB, GOTTWALd (2010), \113, pár. 7.
} 
de un documento público sobre designación de funcionario público, disponibilidad de este y decisión); $\ 418$ (valor probatorio de documentos públicos con otros contenidos) y $\ 438$ inc. $2^{\circ}$ (veracidad de documentos públicos emitidos en el extranjero). ${ }^{84}$

\section{ii. El principio de la libre formación del razonamiento judicial}

La libre valoración de la prueba establece como requisito al momento de adoptar una decisión jurisdiccional, el razonamiento del juez sobre la veracidad de la prueba recaída en la existencia de un hecho discutido. ${ }^{85}$

Dichas decisiones judiciales se basan en un complejo proceso racional, en el cual el rol decisivo no recae en las evaluaciones personales del juez particular, ${ }^{86}$ sino principalmente en fundamentos objetivos, determinantes para lograr la convicción judicial. ${ }^{87}$ Por medio de dichos fundamentos se pretende evitar que la decisión sobre la existencia o inexistencia de un hecho se sustente por ejemplo en apreciaciones arbitrarias o motivadas por razones de carácter emocional. ${ }^{88}$ Dicho imperativo se refuerza toda vez que de acuerdo con el $\int 286$ inc. $1^{\circ}$, segundo enunciado, el juez tiene la obligación de fundamentar su sentencia indicando expresamente las razones objetivas que motivaron su convicción.

El principio de la libre valoración de la prueba posibilita asimismo al juez, a partir del análisis de hechos no discutidos, o ya acreditados, arribar a conclusiones respecto de hechos aun controvertidos. ${ }^{89}$ De acuerdo con Musielak, la valoración de hechos en el marco de la valoración judicial de la prueba se produce fundamentalmente con ayuda de las máximas de la experiencia de que dispone el juez, las cuales aplica en base a las reglas del conocimiento. ${ }^{90}$ Es precisamente en dicho contexto donde la prueba de indicios, la prueba prima facie y las presunciones de hecho encuentran su fundamento.

A este respecto surge inevitablemente la duda relativa al grado de certeza que se requiere por parte del juez para tener por probado un hecho controvertido. El Tribunal Supremo alemán (BGH) ha señalado en el famoso caso Anastasia ${ }^{91}$, que $[\mathrm{u}] n$ libre convencimiento exento de toda duda no se encuentra contemplado en la legislación. El convencimiento del juez se puede lograr aun cuando subsistan dudas, o cuando con la prueba disponible se bubiese podido arribar a una interpretación diferente de los hechos. El juez deberá en casos controvertidos actuar con el grado de certeza utilizado en la vida cotidiana, el cual si bien

\footnotetext{
${ }^{84}$ MusielaK (2012b), pár. 458; Rosenberg, Schwab, GOTTWALd (2010), \113, pár. 8.

${ }^{85}$ MusielaK (2012b), pár. 459.

${ }^{86}$ MusielaK (2010), p. 562.

87 MusielaK (2012b), pár. 459; MusielaK (2010), p. 562.

88 JAUERNIG y HeSS (2011), \ 49, pár. 18.

${ }^{89}$ SJK, LEIPOLD (2008), \286, pár. 128.

${ }^{90}$ MusielaK (2012b), pár. 460.

${ }^{91}$ BGH NJW 1970, 943. Cfr. BGH VersR 1959, 632.
} 
permite acallar las dudas, no implica necesariamente excluirlas del todo. Este estándar de certeza ha sido sostenido con posterioridad de manera casi uniforme por la jurisprudencia. ${ }^{92}$ En la doctrina en cambio el panorama no es del todo claro, inclinándose esta por quienes ${ }^{93}$ exigen como estándar de convencimiento un "alto grado de probabilidad" formulado ya sea bajo la fórmula de grado de certeza que excluya toda duda razonable ${ }^{94} \mathrm{o}$ bien de probabilidad rayana en la certeza. ${ }^{95} \mathrm{El}$ análisis crítico de las distintas posturas formuladas a este respecto excede el alcance de este trabajo.

Considerando la imposibilidad de alcanzar una verdad ausente de toda duda respecto de la apreciación de hechos pasados, ${ }^{96}$ subsistirán siempre dudas abstractas, no atendibles, que no necesariamente alteran la veracidad del resultado alcanzado. ${ }^{97}$

\section{b. La prueba prima facie como consecuencia de la libre valoración de la prueba}

La prueba prima facie, en cuanto instrumento jurídico desarrollado por la jurisprudencia, ${ }^{98}$ opera no como un medio de prueba especial, sino como el empleo de principios basados en la experiencia bumana a nivel de formación de la convicción judicial. ${ }^{99}$ Como caso excepcional encuentra, respecto de una hipótesis concreta, reconocimiento legal en el $\$ 371$ a inc. $1^{\circ}$.

Reviste especial relevancia para nuestra investigación el estudio de la prueba prima facie, no solo porque parte importante de la doctrina ha asimilado o subsumido las presunciones de hecho dentro de esta institución, ${ }^{100}$ negando en consecuencia su autonomía conceptual, sino fundamentalmente porque de acuerdo con lo aquí dispuesto la estructura de las presunciones de hecho encuentra su punto de partida en la teoría de la prueba prima facie. Para conocer los alcances precisos de dicha relación, debemos en primer término analizar el alcance y significado de este instrumento jurídico.

\footnotetext{
92 BGH NJW 2003, 1116, 1117; 2004, 777, 778; 2008, 1381, 1382; BGH VersR 1959, 632; cfr. SCHWAB (2012), pár. G 485 nota al pie. 23; FOERSTE en: MuSIELAK (2012a) entre otros, \286, pár. 19; SCHWAB (2012), pár. G 485.

${ }^{93}$ MusielaK (2010), p. 562.

${ }^{94}$ BGH NJW 1956, 21; BGH VersR 1959, 632; BGHZ 18, 311 (318); cfr. MUSIELAK (2010), p. 562.

${ }^{95}$ RGH 51, 127; 58, 130 s. en: MuSIELAK (2010), p. 562 nota 15.

${ }^{96}$ MusielaK (2010), p. 563.

${ }^{97}$ NJW-RR 1988, 789; cfr. MusielaK (2010), p. 563; MusielaK, FoERSTE (2012a), \286, pár. 19.

98 Musielak (2012b), pár. 463; MK, PrÜtTing (2013), \286, pár. 48; JAUERnig y HeSs (2011), 』 50, pár. 19; SJK, LEIPOLD (2008), \286, pár. 128.

99 BGH NJW 1998, 79; Rosenberg, SCHWAB, GotTwald (2010), \113, pár. 16; en igual sentido vid. SJK, LEIPOLD (2008), \286, pár. 132.

${ }^{100}$ En igual sentido: JAUERNIG y Hess (2011), \50, pár. 19.
} 


\section{c. El curso de acontecimientos típico como punto de partida de la prueba prima facie}

La acreditación de hechos tomando como punto de partida sucesos de la vida cotidiana y los conocimientos científicos de nuestros tiempos, posibilitan al juez a arribar a conclusiones vinculantes en el marco de la valoración que este efectúa de la prueba. ${ }^{101}$

En casos difíciles, en los cuales determinados déficits de información referidos a la determinación de los hechos en el proceso civil ${ }^{102}$ no pueden ser suplidos por la producción de prueba efectuada por las partes, o cuando el juez no cuenta con la posibilidad de determinar la existencia de un hecho controvertido por medio de la prueba tradicionalmente entendida como directa, ${ }^{103}$ cobran aplicación las conclusiones derivadas del análisis de los sucesos de la vida cotidiana. ${ }^{104}$

Por medio de la aplicación de reglas de la experiencia puede el juez en el marco de la prueba prima facie, como acertadamente sostiene Prütting, probar la culpabilidad o la causalidad, sin necesidad de acreditar cada una de sus particularidades, ni el modo en que realmente sucedieron los hechos en el caso concreto. ${ }^{105}$

\section{d. Las diferentes categorías de reglas de la experiencia}

En el ámbito de la vida diaria, podemos encontrar distintos grupos de reglas de la experiencia, de disímil calidad y de variable posibilidad de aplicación. ${ }^{106}$ Para determinar cuáles de estas reglas de la experiencia resultan idóneas para construir una prueba prima facie, debemos analizar las distintas categorías en las cuales dichas reglas han sido agrupadas por la doctrina.

La mayor fuerza probatoria corresponde a las llamadas reglas de la experiencia absoluta. ${ }^{107}$ Estas corresponden a leyes que no admiten excepción alguna y que por lo tanto,

\footnotetext{
101 MusielaK (2012b), pár. 464; MK, PrÜTTING (2013), \286, pár. 48, s.; SJK, LEIPOLD (2008), 』 286, pár. 131.

102 Rosenberg, SCHWAB, GotTWALd (2010), \113, pár. 17.

${ }^{103}$ Allner (1993), p. 66.

104 Cfr. BGH NJW 1998, 79. Pese a que en el presente trabajo se ha optado por mantener la clasificación efectuada por la doctrina tradicional entre prueba directa e indirecta, esta distinción se efectúa exclusivamente para fines metodológicos sin que importe una distinción ontológica o cualitativa. En efecto, la diferenciación entre ambas categorías tradicionalmente sostenida desconoce que el análisis y posterior valoración de todo elemento de prueba allegado al juicio se produce por medio de un proceso interpretativo en el que entran en consideración los saberes, la experiencia y el conocimiento del juzgador.

105 MK, PRÜTTING (2013), § 286, pár. 64.

106 MK, PRÜTTING (2013), \286, pár. 56; HAINMÜLLER (1986), p. 23.

107 MK, PRÜTTING (2013), \ 286, pár. 57; HAINMÜLLER (1986), pp. 27 ss.
} 
de acuerdo al razonamiento bumano, son enteramente vinculantes. ${ }^{108} \mathrm{La}$ certeza absoluta que estas otorgan permite concluir que contra ellas no resulta posible admitir prueba en contrario. ${ }^{109}$ Ejemplos de esta clase de reglas de la experiencia corresponden, por ejemplo, al hecho de no poder estar al mismo tiempo en dos lugares distintos, o la prueba de identidad, producida por el análisis de huellas digitales. ${ }^{110}$

Como segunda categoría encontramos las llamadas máximas de la experiencia. Estas describen sucesos causales de típica ocurrencia, que contienen indicios suficientes para deducir una causa concreta o un curso causal determinado. ${ }^{111}$ Estas reglas, a diferencia de las ya analizadas reglas absolutas, no rigen sin excepción. ${ }^{112}$ Por el contrario, las máximas de la experiencia al representar sucesos de la vida cotidiana, que muestran conductas repetidas y usuales, permiten advertir al juez con una alta probabilidad estadística, sobre la existencia de un determinado resultado esperable. ${ }^{113}$

La doctrina ha señalado que las máximas de la experiencia ${ }^{114}$ para ser tales deben cumplir con tres requisitos: representar una conducta usual, repetida, y cuya interpretación represente al estado actual del conocimiento humano.

En opinión de la jurisprudencia, el suceso inferido debe transcurrir $a$ primera vista (prima facie) dentro de los estándares ya referidos por la doctrina para hechos similares, enmarcándose así en un modelo abstracto de realización de los hechos, asimilable al caso concreto. ${ }^{115}$

Encontramos abundantes ejemplos de máximas de la experiencia en el ámbito del transporte, ${ }^{116}$ fundamentalmente en la responsabilidad derivada del no acatamiento de las reglas del tránsito, y de la conducción fuera de la calzada. Más adelante revisaremos estos y otros ejemplos.

De las ya referidas máximas de la experiencia se distinguen a su vez las reglas simples de la experiencia, las que representan una baja probabilidad de ocurrencia de un hecho esperable y que por lo tanto no resultan por si solas suficientes para dar

\footnotetext{
108 MK, PRÜTTING (2013), \286, pár. 57.

${ }^{109}$ Ibíd.

${ }^{110}$ Ibid.

111 Rosenberg, SCHWAB, GOTTWALd (2010), \113, pár. 18; HAINMÜLleR (1986), p. 179.

112 MK, PRÜTTING (2013), \286, pár. 58.

${ }^{113}$ BGH NJW 2004, 3623; BGH NJW 2005, 2398; cfr. MK, PRÜTTING (2013), 』 286, pár. 48, 58; en igual sentido: JAUERNIG y HeSS (2011), \50, pár. 21; LÜKE (2011), pár. 279; HAINMÜLlER (1986), p. 179.

114 MK, PRÜTTING (2013), 』 286, pár. 58; RosenberG, SCHWAB, GOTTWALD (2010), 』113, pár. 17; HAINMÜLLER (1986), pp. 26 ss.

115 BGH NJW 1991, 230 (231).

116 MK, PRÜTTING (2013), 』 286, pár. 58; BGH NJW 1991, 230; 1980, 2125; 1982, 1595; 1982 , 2668; 1964, 1371; 1976, 1317; 1952, 1137.
} 
por acreditada la ocurrencia de un hecho. ${ }^{117}$ Como a diferencia de las máximas de la experiencia, las reglas simples no poseen vigencia general, solo pueden tener cabida para la valoración de la prueba, como analizaremos posteriormente, dentro del ámbito de la prueba de indicios. ${ }^{118}$

Por último, debemos diferenciar las reglas de la experiencia de los simples prejuicios, cuya probabilidad de constatación es tan baja que a ellos no se les confiere valor probatorio alguno. ${ }^{119} \mathrm{La}$ jurisprudencia ha señalado, por ejemplo, que hechos como la creencia que la novia al momento de los esponsales se mantiene virgen, ${ }^{120}$ de que un taxista experimentado jamás chocará contra un vehículo estacionado, ${ }^{121} \mathrm{o}$ de que un testigo antes sancionado penalmente es no creíble, ${ }^{122}$ corresponden a meros prejuicios, desprovistos de valor probatorio alguno.

\section{e. Las máximas de la experiencia como fundamento de la prueba prima facie}

$\mathrm{El} \mathrm{BGH}$ ha establecido que las experiencias de la vida [...] conocen sucesos, que son tan usuales y reiterados, que ya desde una primera mirada (prima facie) permiten concluir una determinada causa o efecto. ${ }^{123}$ Este proceso sucede en sede de libre valoración de la prueba, por medio del empleo de reglas de la experiencia que representan cursos tipicos de acontecimientos ${ }^{124}$ y que poseen propiedades concretas, ${ }^{125}$ que permiten al juez arribar a una decisión jurisdiccional. En este sentido, la tipicidad de la conducta, esto es su reiteración y habitualidad, constituye el elemento central de la prueba prima facie, ${ }^{126}$ en el sentido de que la conexión casual entre un hecho determinado y un resultado concreto resulta tan usual, que la probabilidad de tenerlo por acreditado alcanza un nivel muy alto. ${ }^{127} \mathrm{La}$ habitualidad y el hecho de que los

117 MK, PRÜTTING (2013), \286, pár. 60; (1983), p. 108; ALLNER (1993), p. 70; HAINMÜLLER (1986), p. 28.

118 MK, PRÜTTING (2013), \286, pár. 60.

119 Ibid. pár. 62.

120 OLG Bamberg FamR 1967, 334, s.

121 AG München, Urt. v. 27.6.1979, en: MK, PRÜTTING (2013), \2 286, pár. 62.

122 Justificadamente rechazado: OLG Bamberg MDR 2004, 647. Otros ejemplos vid. MK, PRÜTTING (2013), \286, pár. 62.

123 BGH NJW 100, 31 (33); NJW 1989, 2876; NJW 2004, 3623; 94, 1880; 96, 1828; 97, 528; 98, 749; 2005, 2454; 2006, 2262; BGH VersR 1991, 460; cfr. SCHELLHAMMER (2007), pár. 518; SJK, LEIPOLD (2008), \286, pár. 519.

${ }_{124}$ NJW 2005, 2614; 2004, 3623; 1994, 1880; 1983, 1380; 1951, 653; 1954, 718; 1960, 818; 88, 2611; 96, 1828; 97, 528; 98, 749; 82, 2447; 78, 2197; 2005, 2454; 2006, 2262; cfr. MK, PRÜTTING (2013), 〔286, pár. 48; MusielaK (2012b), pár. 463; ZÖLLER, GREGER (2010), 』284, pár. 29; SCHWAB (2012), pár. G 489; LEPA (1992), p. 129.

125 MK, PRÜTTING (2013), \286, pár. 56.

126 SJK, LEIPOLD (2008), \286, pár. 135; LEPA (1992), p. 130; ZÖLLER, GREGER (2010), \ 284, pár. 29; Musielak (2012b), pár. 463; Rosenberg, SchWab, GOtTWald (2010), 』 113, pár. 18; HAINMÜLLER (1986), p. 31.

${ }^{127}$ BGH VersR 1991, 460; BGH NJW 2006, 2262; 2004, 3623; BGH NJW 1954, 1119; 51, 360; RGZ 134, 241. 
Correa - La presunción de hecho como figura jurídica en el derecho procesal civil alemán

acontecimientos se condigan con las reglas de la vida diaria corresponden a características propias de este tipo de sucesos. ${ }^{128}$

Para que el tribunal pueda por medio de la prueba prima facie (a diferencia como veremos, de la prueba de indicios) tener por acreditado un hecho controvertido, deben poseer las reglas de la experiencia una entidad tal, que permitan obtener el razonamiento aun sin consideración ni valoración de otros antecedentes del caso concreto. ${ }^{129}$ En este entendido, son solo las máximas de la experiencia las que permiten alcanzar dicho estándar; por medio de su aplicación, puede el juez -sin consideración de otros medios de prueba- ${ }^{130}$ lograr la acreditación de hechos de acuerdo con el estándar para estos efectos exigido. ${ }^{131}$

Una regla de la experiencia simple ${ }^{132}$ podrá, por el contrario, únicamente conducir a una probabilidad predominante, siendo con ello insuficientes para fundamentar la existencia de una prueba prima facie. ${ }^{133}$

\section{f. Ámbito de aplicación de la prueba prima facie}

El ámbito de aplicación de la prueba prima facie se reduce, por razones históricas, ${ }^{134}$ a la determinación de la causalidad y de la culpabilidad; ${ }^{135}$ siendo generalmente utilizada en procesos donde lo que se discute es la procedencia de una indemnización de perjuicios. ${ }^{136}$

Respecto de decisiones individuales, ${ }^{137}$ se discute si la prueba prima facie resulta o no aplicable. Mientras una parte de la literatura ${ }^{138}$ acepta dicha posibilidad,

\footnotetext{
128 BGH NJW-RR 1988, 789; cfr. LEPA (1992), p. 130; SJK, LEIPOLD (2008), \ 286 pár. 128.

129 ANZINGER (2006), pp. 74 s.; HAINMÜLLER (1986), pp. 179 ss.

130 BAUMGÄRTEL (1990), p. 50; WSK, ASSMANN (2012), \ 292, pár. 13.

131 BGH NJW 1998, 79; 1987, 2876; BGH NJW-RR 1988, 789 (790); cfr. MK, GRUNSKY (2013), 』 249, pár. 139; MK, PRÜTTING (2013), \286, pár. 49, 51, s. 64; Walter (1977), p. 282; ANZINGER: Anscheinsbeweis (nota 129), p. 74.

132 Ver entre otros la jurisprudencia sobre el llamado caso Nichtschimmerfall (BGH NJW 1954, 1119)

y el llamado Luesfall (BGZ 11, 227; cfr. MK, PRÜTTING (2013), \286, pár. 61.

133 ZÖLLER, GREGER (2010)), \284, pár. 29; SJK, LEIPOLD (2008), \286, pár. 128.

134 ANZINGEN, p. 29, ss.; Allner (1993), p. 124.

135 BGH NJW-RR 1988, 789; 1991, 230; 1956, 1638; VersR 1956, 577; cfr. ANZIGER (2006), p. 31; HAinMÜller (1986), p. 87; MusielaK (2012b), pár. 467; RoSENBERG, SCHWAB, GotTWALD (2010), 』113, pár. 19; HolZHAMmer (1986), p. 212; JAUERNiG y HeSs (2011), 』50, pár. 23; LÜKE (2011), pár. 279; MK, PRÜTTING (2013), \ 286, pár. 59; SCHELLHAMMER (2007), pár. 520; ZÖLLER, GREGER (2010), \284, pár. 30, ss.; MUSIELAK, FOERSTE (2012a), \286, pár. 26, ss.; SJK, LEIPOLD (2008), \286, pár. 132, ss.; SCHWAB (2012), pár. G 489; LEPA (1992), p. 129, s. Opinión discrepante: vid. RosenberG, SCHWAB, GOTTWALD (2010), \113, pár. 32; MusielaK (2012b), pár. 467; LÜKE (2011), pár. 279; WALTER (1979), p. 214, s.; WALTER (1977) p. 284. Para una exposición general de la problemática, vid. SJK, LEIPOLD (2008), \286, pár. 136; SCHELLHAMMER (2007), pár. 522, ss. 136 SJK, LEIPOLD (2008), \286, pár. 128; LÜKE (2011), pár. 279; SCHELLHAMMER (2007), pár. 520; LEPA (1992), p. 130.

137 Ejemplos en: SJK, LEIPOLD (2008), \286, pár. 174, ss.; SCHWAB (2012), pár. 491a.
} 
ha sido esta rechazada con justificada razón por la jurisprudencia mayoritaria ${ }^{139} \mathrm{y}$ otro sector de la literatura. ${ }^{140}$ En este entendido, cabe tener presente que respecto de decisiones individuales (por ejemplo, el suicidio intencional) no nos encontramos en presencia de acontecimientos usuales y reiterados, aplicables a otros eventos; el elemento esencial de la prueba prima facie, la tipicidad, falta en estos casos. ${ }^{141}$ Cuando producto del carácter único e irrepetible que revisten las decisiones personales se renuncia a la tipicidad como elemento conector entre un hecho controvertido y la experiencia humana, se impide que la experiencia pueda fundamentar un juicio certero, y con ello posibilitar la plena convicción del juez. Bajo estas circunstancias podrán las experiencias derivadas de decisiones individuales tener vigencia únicamente dentro de la categoría general de la prueba de indicios.

\section{i. La prueba prima facie para la determinación de la causalidad}

La prueba prima facie para la determinación de la causalidad ${ }^{142}$ permite en primer lugar determinar el vínculo causal entre el daño producido no controvertido y la no controvertida infracción de deberes. ${ }^{143}$ Asimismo, se puede establecer como causa de un determinado resultado un comportamiento acreditado, así como a la inversa, determinar ciertas conductas generadoras de resultados usuales ya acreditados, como causa. ${ }^{144}$

En estas constelaciones se produce la subsunción al caso concreto. Será precisamente el juez el que con ayuda de las máximas de la experiencia escogerá como causa aquella que revista la mayor plausibilidad dentro de las diferentes opciones. ${ }^{145}$ Contrario sensu no se podrá fundar una prueba prima facie cuando entre dos posibilidades una aparezca simplemente como más plausible que la otra. ${ }^{146}$

\footnotetext{
138 SJK, LEIPOLD (2008), \286, pár. 136, 174; LAUMEN en BAUMGÄRTEL et al. (2009), \14, pár. 17. ${ }_{139}$ BGH NJW 1993, 3259; 1991, 1948; 1988, 2040; 1987, 1944; 1980, 122; 1960, 818; 1987, 1944 ; 1968, 2139; 1983, 1548 (1551); cfr. ANZINGER (2006), p. 36; ZÖLLER, GREGER (2010), \ 284, pár. 31; LEPA (1992), p. 130; opinión discrepante: BGH NJW 1958, 177; 1962, 1099 (1100); 1967, 1222 (1223); 1974, 795 (796).

140 Walter (1977), p. 278 s.; ZÖLler, Greger (2010), \ 284, pár. 30; RosenBerG, SchWAB, GOTTWALD (2010), \113, pár. 31; LEPA (1992), p. 130.

${ }^{141}$ LePa (1992), p. 130; Rosenberg, SCHWAB, GOtTWALd (2010), \113, pár. 31.

142 BGH NJW 2001, 1140 (1141); 1994, 1880; cfr. Rosenberg, SCHWAB, GOTTWALD (2010), $\int 113$, pár. 20.

143 BGH NJW 2001, 1140 (1141); cfr. ROSENBERG, SCHWAB, GOTTWALD (2010), 』113, pár. 20.

144 BGH NJW 1997, 528; BGH VersR 1956, 577; cfr. RosenBERG, SCHWAB, GOTTWALD (2010), 』 113, pár. 20.

145 MusielaK (2012b), pár. 466.

146 BGH NJW-RR 1988, 789; BGH 1966, 1263; cfr. SJK, LEIPOLD (2008), 』 286, pár. 128; SCHELLHAMMER (2007), pár. 519.
} 


\section{ii. La prueba prima facie para la determinación de la culpabilidad}

En los casos de acontecimientos típicos puede tenerse por acreditada la culpabilidad, cuando la causa del daño, de acuerdo a la experiencia cotidiana, se atribuye a un comportamiento considerado como culpable. ${ }^{147}$ En el ámbito de la determinación de la culpabilidad es especialmente relevante el empleo de la prueba prima facie respecto de accidentes de tránsito ${ }^{148}$ y en relación con casos de responsabilidad médica. ${ }^{149}$

\section{iii. Ejemplos ${ }^{150}$}

Como señalamos, gran relevancia práctica posee la prueba prima facie en casos de accidentes de tránsito. ${ }^{151}$ En esta área, y a modo meramente ejemplar, reconoce la jurisprudencia la culpabilidad del conductor por medio de prueba prima facie cuando el vehículo que conduce se ha estrellado contra un árbol ${ }^{152}$ o contra un poste, ${ }^{153}$ o bien cuando el conductor sin razón aparente abandona la calzada. ${ }^{154} \mathrm{La}$ jurisprudencia ha aceptado asimismo la responsabilidad por medio de una prueba prima facie del conductor que adelanta, en un accidente ocasionado durante una maniobra de adelantamiento, ${ }^{155}$ así como la culpabilidad de quien conduce por la vía izquierda en casos de choque frontal, ${ }^{156}$ al igual que la responsabilidad de quien adelanta en un cruce. ${ }^{157}$ Una prueba prima facie conduce a la acreditación de la imprudencia grave del conductor $^{158}$ y la acreditación de la relación causal como consecuencia de un accidente en el que uno de los involucrados conducía bajo efectos del alcohol. ${ }^{159}$ Una prueba prima facie se construye asimismo para establecer la responsabilidad del conductor que adelanta, en los casos de accidente producido con motivo de una maniobra de adelantamiento. ${ }^{160}$ En accidentes producidos entre un automóvil y un tren sobre la línea ferroviaria, la jurisprudencia sostiene la

\footnotetext{
147 Rosenberg, SCHWAB, GOTTWALD (2010), \113, pár. 25.

148 BGH NJW 1966, 1828; NJW-RR 1986, 383; BGH NJW 1991, 230.

149 Rosenberg, SCHWAB, GOTTWALD (2010), \113, pár. 25.

150 Otros ejemplos vid. SJK, LeIPOLD (2008), \286, pár. 143, ss.; SCHWAB (2012), pár. 491A; ZÖLLER, GREGER (2010), \284, pár. 30, ss.; ROSENBERG, SCHWAB, GOTTWALD (2010), \113, pár. 21, ss.; sobre la antigua jurisprudencia: HAINMÜLLER (1986), p. 84, ss.

151 SJK, LEIPOLD (2008), \286, pár. 143.

152 BGHZ 8, 239; MDR 1959, 480; cfr. SJK, LEIPOLD (2008), \ 286, pár. 144.

153 OLG München VersR 1970, 630 (631); cfr. SJK, LEIPOLD (2008), \286, pár. 144.

154 OLG Stuttgart VersR 1974, 502; BGH VersR 1966, 693; 1959, 445; 1955, 189; 1956, 589 (590); 1956, 799; BAG NJW 1967, 269; cfr. SJK, LEIPOLD (2008), \286, pár. 144.

155 BGH NJW-RR 1989, 670; cfr. RosenberG, SCHWAB, GOTTWALD (2010), 』113, pár. 26.

${ }^{156}$ BGH NJW 1962, 796; cfr. SJK, LEIPOLD (2008), \ 286, pár. 145.

157 BGH VersR 1958, 781; cfr. SJK, LEIPOLD (2008), \ 286, pár. 145.

158 OLG Köln VersR 1969, 1014; BGH VersR 1962, 252.

${ }^{159}$ BGHZ 18, 311; BGH VersR1982, 968; 1966, 585; 1986, 141; 1964, 846; BGH NJW 1976, 897; cfr. SJK, Leipold (2008), \ 286, pár. 146; ZÖLLER, GREGER (2010), \ 284, pár. 30; ROSENBERG, SCHWAB, GOTTWALD (2010), \113, pár. 22. Contra la presunción de responsabilidad en casos de baja ingesta de alcohol: BGH NJW 1988, 1846.

160 BGH NJW 1975, 312; OLG Hamm VersR 1954, 513; BGH NJW-RR 1986, 384; OLG Frankfurt VersR 1982, 1079; cfr. SJK, LEIPOLD (2008), \286, pár. 149.
} 
existencia de una prueba prima facie para acreditar la responsabilidad del conductor del vehículo, ${ }^{161}$ así como en casos de accidentes en motocicleta, para acreditar la relación causal entre las lesiones corporales y el no uso de casco por parte del motociclista. ${ }^{162} \mathrm{La}$ jurisprudencia afirma igualmente la existencia de una prueba prima facie en casos de accidentes del tránsito para establecer el vínculo causal entre el sistema de frenado defectuoso de un vehículo y un accidente; ${ }^{163}$ entre el hecho de mantener un vehículo con iluminación defectuosa y un accidente producto del adelantamiento a una motocicleta, ${ }^{164}$ entre el no mantener la pista de circulación derecha y el choque frontal con un vehículo en el sentido contrario, ${ }^{165}$ así como entre el no ajustar el cinturón de seguridad y los daños producidos con ocasión de un accidente. ${ }^{160}$

Uno de los primeros casos de aplicación de la prueba prima facie corresponde al llamado caso de colisión de barcos. ${ }^{167}$ En los casos en que una embarcación en movimiento colisiona con un barco debidamente anclado, se establece prima facie la responsabilidad del personal del buque en movimiento, al haber actuado en contra de las reglas propias del tráfico fluvial. ${ }^{168}$

En el ámbito de la responsabilidad médica posee la prueba prima facie un rol determinante, especialmente para establecer la causalidad existente entre la falta de consentimiento informado por parte del paciente respecto de una operación y los daños a la salud producidos con posterioridad a esta. ${ }^{169}$ La prueba prima facie permite establecer además la responsabilidad del médico tratante por las lesiones producidas tras la entrada de aire en una inyección, tras haber dejado elementos extraños (dependiendo de su tipo y volumen) en el interior del cuerpo tras una operación, ${ }^{170}$ así como la relación causal entre la infección con $\mathrm{VIH}^{171}$ y la transfusión de sangre, en casos en los que el paciente no pertenece a un grupo de riesgo.

\footnotetext{
161 OLG Düsseldorf VersR 1978, 852; BGH VersR 1977, 60 (61); cfr. SJK, LEIPOLD (2008), \ 286, pár. 151.

162 BGH NJW 1983, 1380; 1980, 2125; cfr. SJK, LEIPOLD (2008), 』 286, pár. 153; ZÖLLER, GREGER (2010), \ 284, pár. 30.

163 BGH VersR 1971, 80; cfr. ZÖLLER, GREGER (2010), \ 284, pár. 30.

164 BGH VersR 1964, 296; cfr. ZÖLLER, GREGER (2010), \284, pár. 30.

165 BGH VersR 1964, 166; cfr. ZÖLLER, GREGER (2010), \284, pár. 30.

166 Rosenberg, SCHWAB, GOTTWALd (2010), \113, pár. 22.

167 ANZINGER (2006), p. 32, s.

${ }^{168}$ BGH VersR 1982, 491; 1965, 560; 1974, 1200; cfr. ANZINGER: Anscheinsbeweis (nota 129), p. 32, s.; SJK, LEIPOLD (2008), \286, pár. 143.

169 OLG Köln NJW 1987, 2302; cfr. RosenberG, SCHWAB, GOTTWALD (2010), 』 113, pár. 21.

170 BGH VersR 1957, 786; 1956, 577; 1952, 180 (181); 1953, 338; BGH NJW 1952, 382; BGHZ 4, 138; cfr. SJK, LEIPOLD (2008), 』 286, pár. 161; ZÖLLER, GREGER (2010), 』 284, pár. 30a; ROSENBERG, SCHWAB, GOTTWALD (2010), \ 113, pár. 28.

171 BGH NJW 1991, 1948; 1991, 1937; 2005, 2614; cfr. SJK, LEIPOLD (2008), 』 286, pár. 161; SCHWAB (2012), pár. 491A; ZÖLLER, GregER (2010), 』 284, pár. 30; RosenBERG, SCHWAB, GOTTWALD (2010), \113, pár. 21.
} 
Por último, la prueba prima facie cumple un papel decisivo para determinar la causalidad y culpabilidad, entre otros, en materia de envío de mercaderías, ${ }^{172}$ accidentes deportivos, ${ }^{173}$ casos de dopaje ${ }^{174}$ y responsabilidad derivada del daño producido por animales, ${ }^{175}$ entre otros.

\section{g. La naturaleza jurídica de la prueba prima facie}

La doctrina mayoritaria ${ }^{176}$ sostiene que la prueba prima facie encuentra su fundamento en la regla de libre valoración de la prueba, consagrada en el $\int 286$, sin alterar en consecuencia la carga objetiva de la prueba.

La pregunta sobre la naturaleza jurídica de la prueba prima facie no resulta en cambio tan evidente. En virtud de su posicionamiento dentro del marco de la libre valoración de la prueba prima facie constituiría, de acuerdo con la doctrina mayoritaria, un instrumento de naturaleza procesal. ${ }^{177}$ Así, en cuanto componente de la valoración de la prueba que efectúa el tribunal ${ }^{178}$ se trataría de una figura procesal conducente a la simplificación de la rendición de prueba. ${ }^{179}$

Sin embargo, si consideramos materias donde los hechos trascienden las fronteras de un determinado país, podría sostenerse su adscripción al derecho material. En dichos casos, surge la pregunta por si el tribunal competente debe simplemente aplicar el derecho procesal de su propio país (lex forl) -caso en que se mantendría la naturaleza procesal del instrumento-, o bien, por aplicación del derecho internacional privado al caso concreto, resulta posible adscribirla dentro del derecho material. ${ }^{180}$ Los alcances de esta investigación no permiten, sin embargo, profundizar en este punto.

Como ya se expuso, la aplicación de reglas de alteración de la carga de la prueba (como las presunciones legales) se encuentra restringida a casos en los que la existencia o inexistencia del hecho controvertido no ha sido concluyentemente

\footnotetext{
172 BGH NJW 1978, 1694; BGHZ 17, 191; cfr. SJK, LEIPOLD (2008), 』286, pár. 157.

173 BGH NJW 1975, 109, 111; OLG Düsseldorf VersR 1980, 270; cfr. SJK, LEIPOLD (2008), \ 286, pár. 163.

174 OLG Frankfurt NJW-RR 2000, 1117; cfr. SJK, LEIPOLD (2008), \286, pár. 164.

175 OLG Koblenz NJW-RR 1998, 1482; cfr. SJK, LEIPOLD (2008), 』 286, pár. 165.

176 De acuerdo a ANZINGER (2006), pp. 40 y 58; ZÖLLER, GREGER (2010), \ 284, pár. 29; en el mismo sentido Rosenberg, Schwab, GotTwald (2010), \113, pár. 32, ss.; MK, PrütTing (2013), 』286, pár. 48; LÜKE (2011), pár. 279; POHLMANN (2011), pár. 379; opinión discrepante BGH NJW 1954, 1119; ZÖLler, GREger (2010), \284, pár. 29; JAUERNIG y Hess (2011), \50, pár. 19.

177 WALTER (1977), p. 279; ANZINGER (2006), p. 58; ROSENBERG, SCHWAB, GOTTWALD (2010), \113, pár. 36; SJK, LEIPOLD (2008), \286, pár. 140 ss.

${ }^{178}$ MK, PRÜtTING (2013), \286, pár. 49; SJK, LEIPOLD (2008), \286, pár. 140.

179 WALTER (1977), p. 284.

180 SCHWAB (2013), p. 3.
} 
acreditada (non liquet). ${ }^{181}$ Dichos supuestos cobran aplicación en los casos en que la parte sobre la que recae la carga de la prueba no ha podido acreditar el hecho alegado a su favor. La prueba prima facie opera justamente en el sentido contrario. ${ }^{182}$ Cuando el juez extrae por medio de las máximas de la experiencia sus consecuencias respecto de la existencia de un hecho controvertido no hace sino evitar los efectos jurídicos del non liquet. ${ }^{183}$

Cuando una parte invoca la aplicación de una prueba prima facie debe en primer lugar exponer las circunstancias concretas, que de acuerdo con la experiencia general posibilitan deducir un determinado curso causal o resultado culpable. ${ }^{184}$ Posteriormente, deben determinarse los presupuestos fácticos ${ }^{185}$ que permitirán dar por acreditada la aludida máxima de la experiencia ${ }^{186}$ (llamados por la jurisprudencia fundamentos de la tipicidad ${ }^{187} \mathrm{y}$, por último, deben ser estos debidamente probados, de acuerdo con las reglas generales. ${ }^{188}$ Cuando el interesado ha logrado acreditar los presupuestos fácticos que permiten al juez tener por probada la causalidad o la culpabilidad por medio del empleo de máximas de la experiencia, puede este tenerlos por acreditados, sin requerir de la producción de prueba adicional. ${ }^{189}$

\section{h. Reducción del estándar de prueba por medio de la prueba prima facie}

Atendida las considerables dificultades que encierra la prueba de la causalidad y de la culpabilidad, la jurisprudencia ha limitado (muchas veces sin explicitarlo), con ayuda de la prueba prima facie, el estándar o medida de prueba. ${ }^{190}$ Así, cuando nos encontramos en presencia de un déficit de información, la jurisprudencia se ha apoyado de la prueba prima facie para ocultar vacíos generando así una simplificación de la actividad probatoria. ${ }^{191}$ Con ello, la situación procesal de la parte sobre la que recae la carga de la prueba se verá sustancialmente mejorada. ${ }^{192}$

Debido a que la prueba prima facie permite al juez afirmar la concurrencia de elementos que fundamentan una pretensión, prescindiendo del conocimiento

\footnotetext{
181 Rosenberg, Schwab, GotTwWald (2010), \113, pár. 33; MK, PrÜtTing (2013), 』286, pár. 51. 182 MK, PRÜtTing (2013), \286, pár. 51; RosENBERG, SCHWAB, GOTTWALD (2010), 』113, pár. 33.

183 ANZINGER (2006), p. 44; ROSENBERG, SCHWAB, GOTTWALD (2010), \113, pár. 33.

184 BGH NJW 2004, 3623; 1991, 230 (231), VersR 1995, 723 (724); cfr. JAUERNIG y HeSs (2011), \

50, pár. 25; 166; ZÖLLER, GREGER (2010), \284, pár. 29.

185 MuSiELAK (2012b), pár. 468.

${ }^{186}$ JAUERNIG y HESS (2011), \50, pár. 25.

187 BGH NJW 1996, 1828.

188 BGH NJW 2004, 3623; 1991, 230 (231), 1982, 2448; VersR 1995, 723 (724); BGH NJW-RR 1988,189; cfr. ZÖLLER, GREGER (2010), \ 284, pár. 29.

189 JAUERNIG y HeSS (2011), 』50, pár. 25; LÜKE (2011), pár. 280.

190 Musielak (2012b), pár. 466; MK, Prütting (2013), \286, pár. 53; Musielak, Foerste (2012a), \ 286, pár. 21.

191 BGH NJW 1994, 1880; 1993, 3259; cfr. ROSENBERG, SCHWAB, GOTTWALD (2010), \113, pár.

17; LÜKE (2011), pár. 279; contra: WALTER (1977), p. 284.

192 LÜKE (2011), pár. 279.
} 
fáctico de estos, su aplicación resulta muchas veces peligrosa. ${ }^{193}$ La reiteración de la conducta y su habitualidad (tipicidad), características esenciales de las máximas de la experiencia, corresponden a una verdadera garantía para el juez, que le permitirá válidamente tener por acreditada la ocurrencia de un hecho controvertido. ${ }^{194}$

Impropio resulta en este sentido la utilización de reglas de experiencia de menor peso y calidad que las que confieren las máximas de la experiencia, para alcanzar -autónomamente- el estándar de prueba necesario. ${ }^{195}$ Una disminución del quantum de prueba necesario no se condice en modo alguno con el tenor literal del $\ 286:{ }^{196}$ la prueba prima facie no legitima en caso alguno una reducción a priori del estándar de prueba, sino exclusivamente una simplificación de esta. ${ }^{197}$

\section{i. Relación entre la prueba prima facie y la prueba de indicios}

La prueba de indicios y la prima facie tienen como fundamento común la aplicación de reglas de la experiencia diaria. ${ }^{198}$ Por medio de ambas pruebas se posibilita el razonamiento judicial no de forma directa e inmediata, sino solo indirectamente por el análisis y aplicación al caso de reglas de la experiencia. ${ }^{199}$ Ambas instituciones encuentran su fundamento en el $\int 286,{ }^{200}$ cuando la prueba producida por los medios de prueba usuales no logra estándar de prueba exigido. ${ }^{201}$

Una primera diferencia entre ambos instrumentos jurídicos radica en la falta de tipicidad de la prueba de indicios; un indicio es propiamente atípico, mientras que la tipicidad es un elemento central de la prueba prima facie. ${ }^{202}$ De este modo, una regla de la experiencia simple que no cumpla con el requisito antes mencionado no posee individualmente la entidad suficiente para que el juez pueda con ella resolver sobre la existencia de un hecho controvertido. ${ }^{203} \mathrm{Su}$ valoración quedará entonces sujeta a un análisis en conjunto con otros antecedentes del caso particular. La prueba prima facie, por el contrario, producto de la referida tipicidad, bastará por sí sola para que el tribunal tenga por acreditado el hecho controvertido. ${ }^{204}$

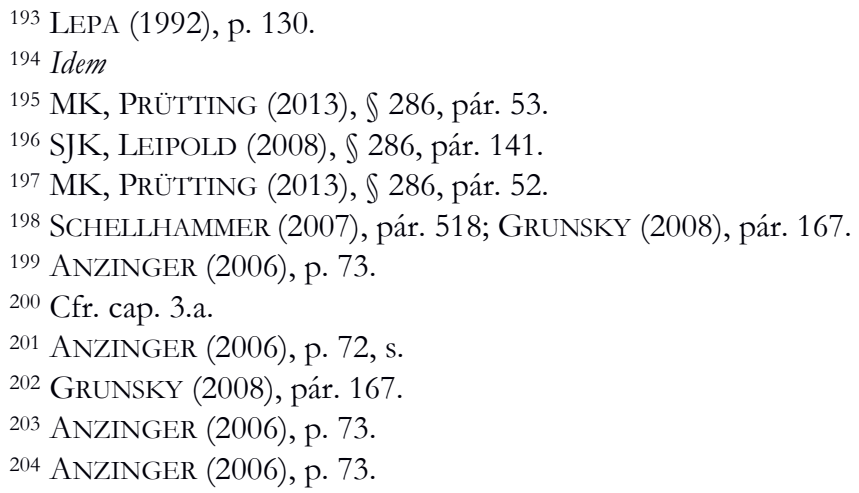


Mientras la prueba prima facie posibilita -por razones históricas- la determinación de la causalidad y la culpabilidad, ${ }^{205}$ el ámbito de aplicación de la prueba de indicios es más amplio. Esta última, al referirse a la acreditación de hechos que no pertenecen, a diferencia de las presunciones legales, a un elemento propio de un precepto legal y ya que solo en conjunto con otros elementos probatorios permiten concluir la existencia o inexistencia de hechos invocados, ${ }^{206}$ permite acreditar cualquier hecho. ${ }^{207}$ La prueba prima facie es, en consecuencia, de acuerdo con su especial configuración, una forma especial de la prueba de indicios referida a hechos típicos. ${ }^{208} \mathrm{La}$ aplicación de la prueba de indicios será entonces subsidiaria a la de la prueba prima facie.

\section{j. Reconocimiento legal de la prueba prima facie}

La prueba prima facie posee reconocimiento legal respecto de una hipótesis específica. En su antigua formulación, reconocía el $\ 292$ a, la existencia de una prueba prima facie sobre la veracidad de la declaración de voluntad contenida en un documento electrónico. La nueva regla contenida en el $\int 371$ a inc. $1^{\circ}$ comprende no solo el antiguo \ 292 a, sino que además establece legalmente la veracidad de toda declaración de voluntad contenida en cualquier medio electrónico dotado de firma electrónica de acuerdo con el $\int 2$, numeral $3^{\circ}$, Ley de firma electrónica $(\operatorname{SigG}) \cdot{ }^{209} \mathrm{La}$ aplicación práctica de la regla del $\ 371 \mathrm{a}$ inc. $1^{\circ}$ ha conducido a una significativa simplificación de la prueba para aquel sobre quien recaiga la carga de esta. ${ }^{210}$

\section{k. Refutación de la prueba prima facie}

Las reglas sobre refutación de la prueba prima facie representan fielmente su compleja estructura. Para el análisis de las diferentes posibilidades existentes para refutar la eficacia de la prueba prima facie no debemos olvidar que esta cumple su función en el ámbito de la libre valoración de la prueba, ${ }^{211}$ modificando exclusivamente la carga concreta (subjetiva) de la prueba. La carga objetivo-abstracta de esta, así como las reglas sobre distribución de la prueba, permanecen incólumes. ${ }^{212}$

Quien desea refutar el efecto de la prueba prima facie debe poner en duda el razonamiento del tribunal respecto de la aplicación de la regla al caso concreto. La parte interesada puede -en primer lugar-impugnar las conclusiones derivadas de la

\footnotetext{
205 Cfr. cap. 3.f.

206 BGH NJW 1970, 946; LAUMEN en BAUMGÄRTEL et al. (2009), \286, pár. 46.

207 HAinMÜLLER (1986), p. 179; ALLNER (1993), p. 65.

208 Rosenberg, Schwab, Gottwwald (2010), 』113, pár. 18; Hainmüller (1986), p. 179;

SCHELLHAMMER (2007), pár. 518; SJK, LEIPOLD (2008), 』 286, pár. 128.

209 MuSiELAK (2012b), pár. 467; LÜKE (2011), pár. 279a.

${ }^{210}$ LÜKE (2011), pár. 279a.

211 Cfr. cap. 3.

212 Rosenberg, Schwab, GotTwald (2010), \ 113, pár. 36; ANZinger (2006), p. 44; LÜKE (2011), pár. 281; SJK, LEIPOLD (2008), \286, pár. 137.
} 
Correa - La presunción de hecho como figura jurídica en el derecho procesal civil alemán

aplicación de la prueba prima facie por medio de una simple contraprueba. ${ }^{213}$ Como sostiene claramente Anzinger, dicha contraprueba no persigue poner en duda la existencia del hecho controvertido, sino simplemente sacudir las conclusiones derivadas de la aplicación de la prueba prima facie. ${ }^{214}$

Dicha contraprueba resulta exitosa cuando la parte que pretende refutar los efectos de la prueba prima facie acredita la existencia de una posibilidad cierta de un acontecimiento o curso causal atípico en el caso concreto, por medio del cual se excluiría la aplicación de una determinada máxima de la experiencia. ${ }^{215}$

Los elementos de hecho en los cuales dicha posibilidad cierta se ampara deben ser acreditados por medio de elementos concretos, ${ }^{216}$ que la parte interesada primero debe invocar y luego acreditar por medio de la plena prueba: ${ }^{217}$ la mera afirmación de hechos que permitirían en abstracto desvirtuar la prueba prima facie no resulta suficiente para privar a esta de su eficacia.

De tal modo, la parte interesada en rebatir la eficacia probatoria de la prueba prima facie no debe acreditar que su comportamiento no fue causal o culpable (ello implicaría exigir la prueba de lo contrario), sino que en el caso controvertido excepcionalmente debe negarse la aplicación de una determinada regla de la experiencia. ${ }^{218}$ Los tribunales han reconocido la posibilidad de acreditar excepciones a los cursos causales normales para el caso concreto. ${ }^{219}$ Es en este sentido donde se aprecia la diferencia entre la prueba prima facie y las presunciones legales y demás reglas de alteración de la carga de la prueba. ${ }^{220}$

De acuerdo con la aplicación de las reglas generales, por medio de las cuales el juez debe alcanzar el estándar de prueba suficiente para tener por

\footnotetext{
213 Rosenberg, SChWAB, GotTwald (2010), \113, pár. 36; Jauernig y Hess (2011), \ 50, pár. 25; ZÖLLER, GREGER (2010), \284, pár. 29.

214 ANZINGER (2006), p. 44.

215 BGH NJW 2012, 608 (609); 2005, 2454; 2004, 3623; 1991, 230 (231); 1983, 1380; 1978, 2032; 1953, 584; 1962, 796; 1954, 1119; 1953, 584; 1952, 1137; BAG NJW 1967, 269; BGH VersR 1995, 723 (724); 1956, 589 (590); BGH NJW-RR 1986, 384; BGHZ 8, 239; cfr. ROSENBERG, SCHWAB, GOTTWALD (2010), \113, pár. 36; ANZINGER (2006), p. 44; MUSIELAK, FOERSTE (2012a), \286, pár. 23; JAUERNIG y HeSS (2011), \50, pár. 25; LÜKE (2011), pár. 281; ZÖLLER, GREGER (2010), \ 284, pár. 29; SJK, LEIPOLD (2008), \286, pár. 139; LEPA (1992), p. 131.

216 SJK, LEIPOLD (2008), \286, pár. 139.

217 BGH NJW 1952, 1137; 1962, 796; 1982, 1595; 91, 230 (231); VersR 1995, 723 (724); BGHZ 6, 169 (170 s.); 8, 239; cfr. Rosenberg, SCHWAB, GOTTWALd (2010), \113, pár. 36; SCHWAB (2012), pár. G 490 nota al pie 28; ZÖLLER, GREGER (2010), \284, pár. 29; LEPA (1992), p. 131.

218 Por ejemplo, en casos de accidente de tránsito sobre la línea ferroviaria no debe el conductor del vehículo probar el cumplimiento de todos los deberes de cuidado, sino simplemente que por ejemplo su acompañante movió el volante, o que el ingreso a la vía ferroviaria se produjo para evitar el atropello de un peatón imprudente. LEPA (1992), p. 131.

${ }^{219}$ BGH NJW 1978, 2032; 1993, 3259; cfr. MuSIELAK (2012b), pár. 468.

${ }^{220}$ Cfr. cap. 2; SJK, LEIPOLD (2008), \286, pár. 137.
} 
acreditado un hecho, la posibilidad abstracta de un curso causal distinto no pondrá en duda el convencimiento adquirido por la vía que analizamos. ${ }^{221}$

Contrario sensu ha rechazado la jurisprudencia la aplicación de la prueba prima facie cuando resulta acreditado que el daño acontecido puede tener como origen dos diferentes causas, en las que cada una de ellas por sí sola es suficiente para producirlo. ${ }^{222}$

Anulado que sea el efecto de la prueba prima facie, resta a la parte sobre la cual recae la carga de la prueba acreditar el hecho por medio de otros medios de prueba. ${ }^{223}$

Estas conclusiones a las cuales ha arribado la jurisprudencia sobre la refutación del efecto de la prueba prima facie, encuentran su parangón en la regulación que el legislador ha establecido en el $\int 371$ a inc. $1^{\circ}$, segunda oración, que establece la refutación de los efectos de la prueba prima facie referida a la veracidad de declaraciones de voluntad emitidas con firma electrónica. En este caso puntual, ha establecido el legislador la cesación del efecto de la prueba prima facie mediante la prueba de elementos que fundamenten una duda cierta sobre si la declaración de voluntad fue efectivamente emitida por el titular de la clave asociada a la firma electrónica. ${ }^{224}$ Dicha disposición reconoce como criterio de supresión de efectos adoptado por el legislador el de posibilidad cierta, equiparable a contrario sensu, a la fórmula duda cierta, reseñada por la doctrina y jurisprudencia ya expuesta.

\section{La presunción de hecho (también llamada presunción fáctica, natural o judicial)}

\section{a. Desarrollo histórico}

A diferencia de lo que sucede con las presunciones legales, las presunciones de hecho no encuentran su fundamento en la ley, sino que corresponden a una creación jurisprudencial. ${ }^{225}$

Sus orígenes pueden remontarse a las llamadas presunciones del derecho común $^{226}$ surgidas en el derecho romano. Ya en el Corpus Iuris Civilis constituían las

\footnotetext{
${ }^{221}$ Cfr. cap. 3.a.ii.

222 BGH NJW 2004, 3623; 1957, 1230; 1978, 2032 (2033); VersR 1995, 723 (724).

${ }^{223}$ LÜKE (2011), pár. 280.

${ }^{224}$ Sobre la carga de la prueba y valor probatorio de la firma electrónica calificada: LüKE (2011), pár. 279a.

${ }^{225}$ De ahí su denominación como presunciones judiciales. Vgl. WSK, ASSMANN (2012), \292, pár. 13; PrÜtTing (1983), p. 50; MK, PRÜTting (2013), \292, pár. 27; LAUMEN en BAUMGÄRTEL et al. (2009), \14, pár. 1; ZÖLLER, GREGER (2010), \284, pár. 33.

226 PRÜTTING (1983), p. 50; MK, PRÜTTING (2013), \292, pár. 7.
} 
presunciones reglas de carga de la prueba, expresamente codificadas, ${ }^{227}$ por medio de las cuales se posibilitaba al juez tener por acreditado un punto discutible, ${ }^{228}$ pero que no resultaban vinculantes para este. ${ }^{229}$

Con la recepción del derecho romano pasaron las presunciones a formar parte del derecho canónico, donde mantuvieron por siglos su vigencia bajo el alero del ius commune. ${ }^{230}$ Posteriormente, una parte de las reglas probatorias contempladas en el derecho canónico, entre estas las presunciones, pasaron por medio de su inclusión en las "Leyes generales para los tribunales prusianos" de 1793 y las "Leyes generales para los Estados prusianos" a formar parte del proceso codificador iusnaturalista propio del derecho europeo-continental de fines del siglo XVIII y comienzos del siglo XIX. ${ }^{231} \mathrm{El}$ objetivo perseguido por el legislador al introducir dichas presunciones como normas codificadas era posibilitar al juez llegar a una solución justa, ${ }^{232}$ sorteando las dificultades prácticas que se generaban en el marco de la entonces imperante prueba legal o tasada.

Pese a que por medio de los $\iint 14$, enunciado $\mathrm{N}^{\circ} 3$, y $16 \mathrm{~N}^{\circ} 1$ de la Ley introductoria de la Ordenanza Procesal Civil de $1877^{233}$ fueron formalmente derogadas las reglas reguladoras de la prueba del derecho común, la verdad es que dicha derogación solo afectó a una parte de estas. En efecto, muchas de estas presunciones fueron reconocidas posteriormente como presunciones legales por el $\mathrm{BGB},{ }^{234}$ mientras que otro grupo significativo, las llamadas presunciones de hecho, de acuerdo con las investigaciones de Planck ${ }^{235}$ conservaron su valor en el marco de la libre valoración de la prueba como "tesoro significativo, heredado de siglos de experiencia acumulada". 236

\section{b. La disparidad de criterios para el tratamiento de las presunciones de hecho}

La confusión que hasta hoy es posible observar con motivo de la aplicación de las presunciones judiciales por parte de los tribunales se explica a partir de la jurisprudencia referida a esta institución.

En efecto, la pregunta sobre las consecuencias jurídicas de las presunciones de hecho no ha sido respondida de manera unívoca por parte de la jurisprudencia

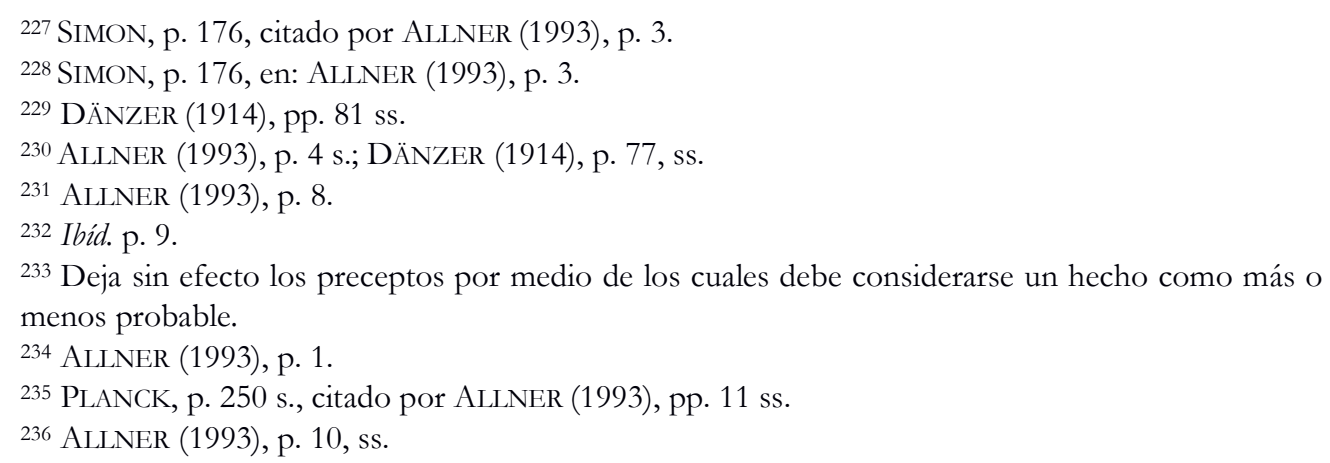


alemana. ${ }^{237}$ En múltiples oportunidades los tribunales han asignado a dichas presunciones un efecto sobre la carga de la prueba, alterando la carga objetiva de esta, ya sea considerándolas como punto de partida para la creación de nuevas presunciones legales, ya sea encasillándolas en una categoría propia dotadas de las mismas consecuencias jurídicas de las presunciones legales, o bien, confiriéndole una función simplificadora de la actividad probatoria. En contraposición a ello, en otros fallos se ha considerado a las presunciones de hecho como reglas de valoración de la prueba, posibilitando con ello el convencimiento del tribunal en el sentido del $₫ 286,{ }^{238}$ ya sea considerándolas como sinónimo de prueba prima facie, como elemento constitutivo de una prueba prima facie, como reglas de simplificación de actividad probatoria en el marco de la libre valoración de la prueba, como una prueba prima facie o una prueba de indicios, dependiendo de su intensidad, o bien como presunciones basadas en un antejuicio.

Los siguientes capítulos se ocupan del análisis de las distintas interpretaciones que la jurisprudencia y la literatura le han otorgado a estas presunciones, así como su análisis crítico.

\section{c. Las presunciones de hecho y su influencia en la carga de la prueba}

\section{i. Las presunciones de hecho como reglas de alteración de la carga objetiva de la prueba en la jurisprudencia ${ }^{239}$}

Muchas veces se ha atribuido a las presunciones judiciales un efecto de inversión de la carga objetiva de la prueba, asimilándolas de esta forma, en mayor o menor grado, a las presunciones legales. Su aplicación se producirá entonces tras la constatación de un non liquet. Como consecuencia de dicha interpretación, deberá el demandado refutar la presunción así entendida solo por medio de la plena prueba.

Respecto de este primer grupo, es posible observar a su vez distintas constelaciones cuyo elemento en común radica en considerar a las presunciones de hecho como reglas con influencia sobre la carga objetiva de la prueba. ${ }^{240}$

\section{ii. Casos en los cuales las presunciones de hecho han sido consideradas como reglas con influencia en la carga objetiva de la prueba, sin indicar su posición dogmática en el campo de la teoría de la prueba}

La más conocida presunción de hecho ${ }^{241}$ señala que ${ }^{242}$ cuando el contenido de un contrato escrito es claro, se presume de hecho la integridad y exactitud de los

\footnotetext{
${ }^{237}$ Laumen en BaumgäRtel et al. (2009), \14, pár. 3; MK, PRÜTTing (2013), 』 292, pár. 27.

${ }^{238}$ Cfr. PRÜTTING (1983), p. 57.

${ }^{239} \mathrm{La}$ siguiente lista no contiene la totalidad de los fallos en los que la jurisprudencia alemana ha utilizado una presunción de hecho, sino exclusivamente los más representativos. Una exposición de todos los dictámenes sería aquí imposible.

240 PrÜtTING (1983), p. 54; MK, PRÜTTING (2013), \292, pár. 27.
} 
acuerdos en él estipulados. Así, el demandante no tiene necesidad de acreditar el contenido del contrato, sino solo su existencia. La parte que alega una discrepancia o anomalía entre el texto y lo efectivamente acordado por las partes, o del contrato mismo en relación con la voluntad de las partes, de acuerdo con la jurisprudencia unánime, deberá acreditar dicha circunstancia refutando la presunción por medio de la plena prueba de lo contrario. ${ }^{243}$ En un caso relativamente reciente, ${ }^{244} \mathrm{el} \mathrm{BGH}$ ha confirmado la función alteradora de la carga de la prueba que se le ha asignado a esta presunción.

Asimismo, la llamada presunción-GEMA ${ }^{245}$ tiene como consecuencia una protección por parte de la "sociedad para la representación musical y derecho de reproducción musical mecánica" (GEMA) respecto de los derechos de representación musicales, la protección de derechos de propiedad intelectual del repertorio musical utilizado en Alemania, así como de la infracción legal derivada de su utilización no autorizada. La presunción-GEMA se refiere a que toda obra musical se presume protegida por GEMA. En estos casos, conduce la presunción a una inversión de la carga de la prueba, que puede rebatirse exclusivamente por medio de la prueba de lo contrario. ${ }^{246}$ En un caso resuelto por el BGH se estableció que el demandante (GEMA) solo debe nombrar el nombre del compositor para establecer que este es miembro de dicha asociación. ${ }^{247} \mathrm{El}$ demandado, quien ha utilizado la obra a su favor, deberá por lo tanto para anular dicha presunción proporcionar respecto de cada obra musical utilizada, el nombre del compositor, y acreditar plenamente que este no es miembro de GEMA o bien que su obra no goza de protección intelectual. ${ }^{248}$

Otra presunción de hecho establecida por la jurisprudencia se deriva de la aplicación de las llamadas "condiciones generales de contratación" (AGB), en los casos en que estas contengan alguna cláusula inadmisible. En estas hipótesis, ha resuelto la jurisprudencia que existe una presunción de hecho sobre la concurrencia de un riesgo de repetición de la conducta. Será entonces propio de estos AGB, su aplicación posterior en una multiplicidad de casos, esto es, la reiteración de la cláusula inadmisible. ${ }^{249}$ Para la eliminación del riesgo de reiteración se requerirá acreditar plenamente la concurrencia de exigentes requisitos: quien estableció el AGB deberá ofrecer

241 PrÜtTing (1983), p. 55 nota al pie 25; ALLNER (1993), p. 42.

242 Esta presunción tiene su origen en la decisión del Tribunal Supremo del Imperio alemán (RG) de 13.06.1902, en: AlLnER (1993), p. 42.

${ }^{243}$ NJW 2002, 3164; 1980, 1680, 1681; 2008, 2852, 2853; 1987, 2012, 2014; 1999, 1702; 2000, 207 ; 1970, 1187; opinión discrepante: LG Mannheim MDR 1977, 231; cfr. LAUMEN en BAUMGÄRTEL et al. (2009), \ 14, pár. 2 y 8; MusielaK, Huber (2012a), \292, pár. 1; WSK, ASSMANN (2012), \292, pár. 16.

${ }^{244}$ BGH NJW 2002, 3164, 3165.

${ }^{245}$ Sobre esta presunción de hecho, vid ALLNER (1993), p. 76, ss.

246 BGH NJW 1986, 1247, 1249; 1249, 1250; cfr. AlLNER (1993), p. 76, ss.; LAUMEN en

BAUMGÄRTEL et al. (2009), \14, pár. 2; WSK, ASSMANN (2012), \292, pár. 14.

247 BGH NJW 1986, 1249.

248 ALLNER (1993), p. 87.

${ }^{249}$ BGH NJW 1981, 2412. 
suficientes garantías y tomar acciones suficientes para evitar una nueva utilización de un AGB inadmisible. ${ }^{250}$

La aplicación práctica de esta presunción se ha extendido a casos de constatación de un peligro de repetición de vulneraciones a la libre competencia, o en supuestos de perturbación a la propiedad. El demandado podrá solo rebatir la presunción acreditando por medio de la plena prueba que una infracción futura con toda seguridad no resulta esperable. ${ }^{251}$

Asimismo, cuando entre los servicios prestados por un corredor de propiedades y el cierre de un contrato existe una relación material y temporal, cobra aplicación una conocida presunción de hecho, que establece la actividad del corredor como causa del cierre del contrato ${ }^{252}$ cuando dicha actividad no resulte controvertida o bien se encuentre acreditada, en casos en que el contrato principal fue cerrado en un plazo de tiempo razonable. ${ }^{253}$ Una refutación de la conexión causal objeto de la presunción entra en relación solo cuando el contrato principal fue celebrado con total independencia de los servicios prestados por el corredor. En estos casos, de acuerdo con la jurisprudencia, la inversión de la carga de la prueba se encontraría justificada, bajo el punto de vista de la justicia. ${ }^{254}$

\section{iii. Las presunciones de hecho como punto de partida para la creación de nuevas presunciones legales}

La jurisprudencia ha establecido en diversas oportunidades que las presunciones de hecho cumplen una función normativa, en cuanto ellas posibilitarían el desarrollo de nuevas presunciones legales con vigencia general, las cuales podrían ser aplicadas como modelo para casos futuros. ${ }^{255} \mathrm{El}$ tratamiento normativo de las presunciones judiciales como presunciones legales cobra especial relevancia en casos en que exista una multiplicidad de sentencias en un sentido determinado. ${ }^{256}$

Se ha establecido en este sentido la existencia de una presunción de hecho de que los socios -aun prescindiendo de las estipulaciones contractuales- han modificado el contrato de sociedad, cuando en una sociedad comercial abierta, sin excepciones ni salvedades, por más de 20 años se han repartido las ganancias mediante un método que se aparta del esquema establecido en el contrato. De

\footnotetext{
250 BGH NJW 1981, 2412; cfr. LAUMEN en BAUMGÄRTEL et al. (2009), \14, pár. 2.

${ }^{251}$ BGH NJW 1999, 356; 1987, 3251, (3252); 1959, 2213; 1980, 1973 (1974); BGH NJW-RR 2011, 1476, 1478; cfr. WSK, ASSMANN (2012), \292, pár. 15; LAUMEN en BAUMGÄRTEL et al. (2009), \ 14, pár. 2.

${ }^{252}$ BGH NJW 1971, 1133, 1135; 1980, 123; 1983, 1849; 1979, 869; NJW-RR 1999, 1502, 1503; cfr.

LAUMEN en BAUMGÄRTEL et al. (2009), 』14, pár. 2, 10.

253 LAUMEN en BAUMGÄRTEL et al. (2009), \14, pár. 2, 10.

254 BGH NJW 1999, 1502; 1983, 1849; 1979, 869.

255 PRÜTTING (1983), p. 53; ALLNER (1993), p. 35.

256 ALLNER (1993), p. 57.
} 
acuerdo con la jurisprudencia, constituiría esta presunción de hecho un verdadero precepto jurídico, cuyo efecto radica en una inversión de la carga de la prueba. ${ }^{257}$

En el ámbito postal, se presume de hecho que en todos los casos de aplicación de máquinas de franqueo para la determinación del monto a pagar el cargo efectuado por el servicio de correo federal se encuentra justificado. La refutación de dicha presunción se efectúa exclusivamente por medio de la prueba de lo contrario (por ejemplo acreditando que en el caso concreto se produjo un cargo erróneo producto de un desperfecto de la máquina), criterio aplicable asimismo como estándar general de refutación de los efectos de la presunción para quien controvierta la veracidad de los registros emitidos por medios técnicos. ${ }^{258}$

\section{iv. Las presunciones de hecho como categoría propia, dotada de los efectos propios de las presunciones legales}

En algunas ocasiones, las presunciones de hecho han sido encasilladas por la jurisprudencia en una categoría propia, con efectos equiparables a los de las presunciones legales, modificando así de la carga objetiva de la prueba. ${ }^{259}$

De este modo, la jurisprudencia ha establecido la existencia de una presunción de hecho aplicable a los alemanes que a partir de 1945 fueron forzosamente conducidos a trabajar en el extranjero. El objeto de la presunción consiste en que los alemanes durante la vigencia de la obligación de efectuar trabajos forzados en espacios reducidos, y encontrándose estos bajo constante vigilancia de autoridad extranjera, corresponden a prisioneros de guerra impropios ${ }^{260}$ en el sentido establecido en el $\int 2$ inc. $2 \mathrm{~N}^{\circ} 2$ lit. a) de la "ley de indemnización de daños producidos a prisioneros de guerra" (Kriegsgefangenenentschädigungsgesets), y por lo tanto resultan susceptibles de ser indemnizados. ${ }^{261}$ Esta presunción de hecho se basa en la reiteración de hechos, por medio del conocimiento judicial previo de una multiplicidad de casos similares. ${ }^{262}$ La jurisprudencia del Tribunal contencioso administrativo federal (BverwG) ha exigido para la refutación de esta presunción la prueba de lo contrario, exigiendo al demandado acreditar que el demandante poseía plena libertad de desplazamiento, del mismo modo como podría bacerlo un ciudadano no alemán, no sujeto a trabajos forzados. ${ }^{263}$

Por último, se ha reconocido la existencia de una presunción de hecho sobre la exactitud de la fecha escrita en un documento privado, cuando dicha fecha sea controvertida. Esta presunción genera como efecto, de acuerdo con la

\footnotetext{
${ }^{257}$ BGH NJW 1966, 826; cfr. LAUMEN en BAUMgäRTEL et. al. (2009), \14, pár. 2; PrütTing (1983), p. 52.

258 OLG Münster NJW 1979, 2531; cfr. PRÜTTING (1983), p. 52.

${ }^{259}$ BVerwGE 17, 141; 8, 98; cfr. PRÜTTING (1983), p. 53, s.

260 BVerwGE 17, 141 (142).

261 BVerwGE 17, 141; 8, 98; cfr. PrütTing (1983), p. 52; Walter (1979), p. 211; Allner (1993), pp. $49 \mathrm{~s}$.

262 BVerwGE 8, 98, 101; cfr. AlLnER (1993), pp. 49 y ss.

263 BVerwGE 17, 141.
} 
jurisprudencia, una inversión de la carga de la prueba por analogía a las reglas sobre presunciones legales. ${ }^{264}$

\section{v. Las presunciones de hecho como prueba de probabilidad en la jurisprudencia}

En su sentencia de 10.01.1951 $1^{265}$ estableció el BGH que la prueba prima facie no corresponde a una prueba de probabilidad, que constituye la base de una presunción de becho revocable, y que por lo tanto justifica una inversión de la carga de la prueba (...).

En este sentido, por medio de la llamada "presunción de los antiguos combatientes" ha señalado el BVerwG que [e]l hecho de que el nombramiento inicial [de un funcionario público] a causa de su vínculo con el Partido Nacionalsocialista, fundamenta la presunción de hecho de que los nombramientos posteriores, o ascensos en la carrera de dicho funcionario, tuvieron como motivo central la afiliación política del involucrado. ${ }^{266}$ Este fallo señaló además los criterios para diferenciar entre la prueba prima facie y la presunción de hecho; mientras la primera tiene lugar exclusivamente respecto de cursos de hecho típicos, y conduce al pleno convencimiento del tribunal (sic), puede por el contrario una prueba de probabilidad "solo" constituir una presunción de hecho. ${ }^{267}$ Esta presunción invierte la carga de la prueba, ${ }^{268}$ en cuanto en el caso concreto el funcionario público debe probar, que su ascenso o nombramiento se debió no solo a razones políticas, sino en igual medida a razones ajenas a ello. ${ }^{269}$

\section{vi. La presunción de hecho como presunción de probabilidad en la literatura}

En su trabajo de 1954 La prueba prima facie y los fenómenos similares define Wassermeyer la presunción de hecho como una regla de carga de la prueba, que opera tras clausura de la fase de valoración de la prueba, y que acarrea como consecuencia que el demandado resulta sin más condenado, a causa de una mera probabilidad. ${ }^{270}$

Las presunciones de hecho operarían, de acuerdo con Wassermeyer, en caso de que se produzca un non liquet. ${ }^{271}$ Así, cuando el juez ve en la práctica los resultados de un non liquet (la demanda debe ser rechazada) como injustos, señala el autor, buscará llegar a otra solución por medio del análisis de acontecimientos

\footnotetext{
${ }^{264}$ KG MDR 1977, 674; cfr. PRÜTTING (1983), p. 53; LAUMEN en BAUMGÄRTEL et al. (2009), @ 14, pár. 7.

265 BGH NJW 1951, 360; PRÜTTING (1983), p. 50; ALLNER (1993), p. 36.

${ }^{266}$ BGH NJW 1956, 761.

267 ALLNER (1993), p. 52.

268 BVerwG NJW 1956, 762; BverwGE 3, 110; 5, 275; 8, 305; cfr. LAUMEN en BAUMGÄrTEL et al. (2009), \ 14, pár. 2; PRÜTTING (1983), p. 51.

${ }^{269}$ BVerwG JR 1960, 429.

270 WASSERMEYER (1954), p. 35.

271 Ibid (1954), p. 34.
} 
típicos. ${ }^{272}$ De esta forma posibilitan las presunciones de hecho en caso de non liquet arribar a un resultado procesal inverso, ${ }^{273}$ con lo que el hecho a probar a causa de la probabilidad dada por una regla de la experiencia se tendrá por aceptado, o bien por supuesto. ${ }^{274}$

Debido a que por medio del juicio de probabilidad el juez aplicará una regla cuya influencia recae en la carga de la prueba, ${ }^{275}$ equiparable en sus efectos a las presunciones legales, ${ }^{276}$ es requisito para su refutación que el demandado -de acuerdo con Wassermeyer- rinda la prueba de lo contrario. ${ }^{277}$

Por último, establece el autor que en estos casos una mera probabilidad conducirá al establecimiento de los hechos, influyendo directamente en la carga de la prueba. ${ }^{278}$ Concluye Wassermeyer afirmando que ya que una condena a base de un juicio basado en una probabilidad, implicaría una vulneración de los principios fundamentales del derecho material y procesal, ${ }^{279}[1]$ a presunción de hecho debiera ser eliminada en todas sus formas. ${ }^{280}$

\section{vii. La teoría de las presunciones de hecho en el marco de la teoría de la probabilidad predominante de Bruns}

Alejado de la mayor parte de la doctrina, ha sostenido Bruns un concepto de presunción de hecho como presunción natural, en cuanto -como Wassermeyerasimila sus efectos con los de las presunciones legales contempladas en el $\ 292 .{ }^{281}$

Bruns, como representante en materia probatoria de la llamada teoría de la probabilidad, ${ }^{282}$ trata a las presunciones de hecho como verdaderas presunciones, ${ }^{283}$ en cuanto según el autor, el concepto de inversión de la carga de la prueba implicaría un mero mayor peso en el juicio de probabilidad del cual estas presunciones estarían supuestamente dotadas. ${ }^{284}$

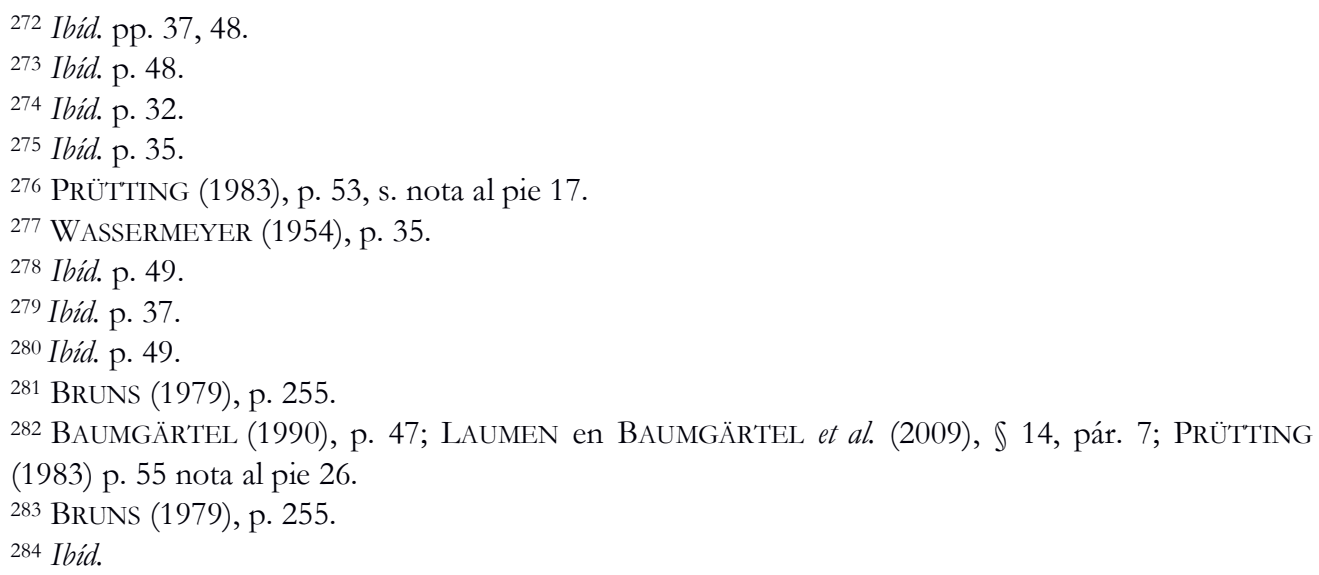




\section{d. Crítica de la comprensión de las presunciones de hecho como reglas de carga de la prueba y su diferencia con las presunciones legales}

Hoy existe unanimidad en la doctrina en que las presunciones de hecho deben distinguirse de las presunciones legales. ${ }^{285}$ Contra cada una de las opiniones recién expuestas, que clasifican a las presunciones judiciales como un instrumento cuyos efectos incidirían en la carga de la prueba, existen poderosas razones que impiden su aceptación.

Como se señaló al comienzo de este trabajo, las presunciones legales revocables representan disposiciones cuyos efectos inciden directamente en la carga objetiva de la prueba entre las partes, produciendo estas una modificación de la carga de alegación. Por medio de ellas ha establecido el legislador expresamente, y con vigencia general, determinados supuestos legales con efecto general, independientemente de si estas corresponden o no a reglas de la experiencia humana: ${ }^{286}$ esta última será entonces normalmente el motivo de establecimiento de una presunción legal, no así necesariamente su contenido. ${ }^{287}$ Por esta razón, no resulta posible equiparar todas las experiencias humanas a dichos instrumentos. ${ }^{288}$

Las reglas de alteración de la carga de la prueba, como lo son las presunciones legales, producen su efecto en situaciones en las que se ha llegado definitivamente a un non liquet. ${ }^{289}$ Sin embargo, en los ejemplos ya descritos de presunciones de hecho no es posible observar dicha situación. Por el contrario, en los casos ya mencionados en los que el tribunal ha aplicado una presunción de hecho precisamente se ha evitado -tal como sucede con la prueba prima faciellegar a un non liquet. ${ }^{290}$ Por ejemplo, en la ya expuesta presunción sobre la integridad y veracidad de un documento privado, cuando la parte interesada no ha podido acreditar la falsedad o falta de integridad del documento, la decisión judicial se basará no en un non liquet, sino en circunstancias acreditadas, como lo es el contenido del documento, fruto del acuerdo contractual. ${ }^{291}$ Lo anterior no permitiría justificar en estos casos una inversión de la carga objetiva de la prueba, como sucede con las presunciones legales. ${ }^{292}$

Por medio de las decisiones que han considerado a las presunciones de hecho como punto de partida de nuevas presunciones legales se ha modificado o bien complementado el derecho vigente. ${ }^{293}$ Esta concepción normativa de las

285 WSK, ASSMANN (2012), \292, pár. 13; MK, PRÜTTING (2013), \292, pár. 7; BAUMGÄRTEL (1990), p. 48; ALLNER (1993), p. 55, ss.; LAUMEN en BAUMGÄrTEL et al. (2009), \14, pár. 13, ss.

286 ALLNER (1993), p. 57.

287 ROSENBERG (1965), p. 211.

288 PRÜTTING (1983), p. 54, s.

289 Cfr. cap. 2.f.

290 PrütTING (1983), p. 55; Allner (1993), p. 57.

${ }^{291}$ LAUMEN en BAUMGÄRTEL et al. (2009), \ 14 pár. 9; cfr. PRÜTTING (1983), p. 55.

292 LAUMEN en BAUMGÄRTEL et al. (2009), \14, pár. 9.

293 ALLNER (1993), p. 35. 
presunciones de hecho, en el sentido de las ya referidas presunciones del ius commune, carecería en principio de legitimidad, en cuanto ellas contendrían como propósito -como Prütting correctamente ha señalado- el reformar la legislación. Las presunciones legales pueden aplicarse, como ya se ha expuesto, solo en casos puntuales, previo reconocimiento legal, lo que respecto de las presunciones judiciales no sucede.

La clasificación de las presunciones de hecho como una categoría con los mismos efectos de las presunciones legales conduce, en cuanto le otorga valor normativo a reglas de la experiencia, a una inadmisible intromisión en los instrumentos propios de la función legislativa. ${ }^{294}$ Aceptar lo anterior implicaría una corrección del ordenamiento jurídico vigente carente de legitimidad. ${ }^{295}$

En relación con la jurisprudencia y autores, que han ordenado a las presunciones de hecho como presunciones de probabilidad, recurren estos al concepto equívoco de "prueba de probabilidad". ${ }^{296}$ De este modo, la teoría de Wassermeyer desconoce que una probabilidad es el máximo grado de acreditación de un hecho, que bajo condiciones normales puede ser alcanzado por el juez. Debido a las limitaciones propias del conocimiento humano no resulta posible establecer la verdad absoluta en un proceso civil, siendo en consecuencia improcedente hablar de plenitud o certeza como grado subjetivo de convicción judicial esperable. Las presunciones de hecho constituyen, de esta forma (como toda prueba), un juicio de probabilidad ${ }^{297}$ suficiente para la constatación de hecho. No es atendible entonces exigir al juez el establecimiento de la verdad absoluta en el marco del $\$ 286 .{ }^{298}$

En contra de la teoría de la probabilidad predominante de Bruns habla en primer lugar el tenor literal del $\int 286$ inc. $1^{\circ}$. Asimismo, reconocer una reducción del estándar de prueba basada en una probabilidad predominante, que justificaría una inversión de la carga de la prueba, conduciría a una ampliación de los fundamentos materiales de la pretensión. ${ }^{299}$ Ello traería como consecuencia una extensión de la responsabilidad carente de sustento legal. ${ }^{300}$

Fuera de lo anterior, en los casos en los cuales la jurisprudencia ha tratado las presunciones de hecho como presunciones de probabilidad (como sucede en el ya comentado caso de los antiguos combatientes), su tratamiento corresponde a un hibrido, con insuperables inconsistencias dogmáticas. Mientras que por un lado (porque no serían capaces de superar el non liquet) tendrían las presunciones de hecho un menor peso en comparación con la prueba prima facie, por otro lado justificarían

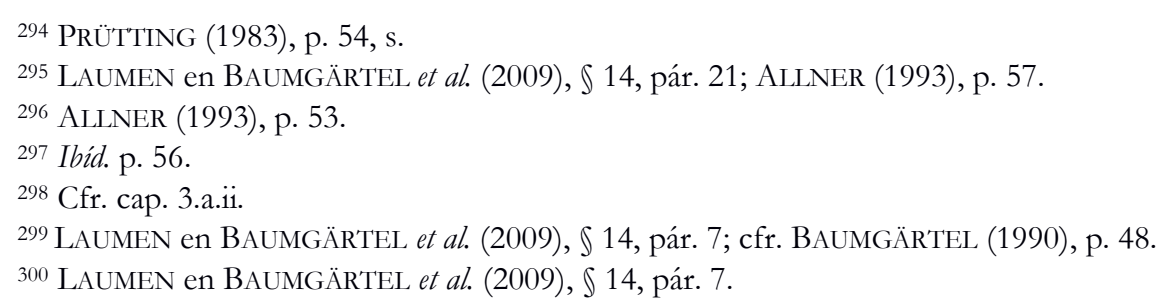


una inversión de la carga de la prueba. ${ }^{301}$ Así, mientras que para la anulación de los efectos de la prueba prima facie (que permiten generar el convencimiento del tribunal) sería solo necesaria una contraprueba, la refutación de las presunciones de hecho, que no poseen la entidad suficiente para evitar el non liquet, solo tendría lugar por medio de la exigente prueba de lo contrario, como sucede respecto de las presunciones legales. ${ }^{302}$ Lo anterior deja al descubierto la inconsistencia del planteamiento.

Por último, puede advertirse como señala Laumen, que para la aplicación de reglas de la experiencia no se trata de una modificación de la distribución del riesgo establecido por el legislador, sino de la valoración fáctica y clasificación de un comportamiento bumano. ${ }^{303} \mathrm{Su}$ legitimación se obtiene de la valoración de circunstancias por medio del conocimiento obtenido a base de la experiencia. ${ }^{304}$ Así, la aplicación y apreciación de reglas de la experiencia para la comprobación de hechos se produce exclusivamente en sede de valoración de la prueba. ${ }^{305} \mathrm{El} \mathrm{BGH}^{306}$ ha señalado acertadamente en este sentido que las [p]resunciones de hecho son aquellas que se basan en la experiencia bumana y en el curso natural de las cosas; ellas se encuentran sujetas a la libre apreciación judicial de la prueba. $^{307}$

En consecuencia, podemos afirmar que las presunciones de hecho conducen exclusivamente a una inversión de la carga de alegación concreta, no siendo posible por medio de estas (al contrario de lo que sucede respecto de las presunciones legales) influir en la carga objetiva de la prueba. ${ }^{308} \mathrm{El}$ Tribunal federal social alemán (BSG) sostuvo en este sentido, en fallo de $29.3 .1963,{ }^{309}$ la clara distinción existente entre las presunciones legales y las de hecho (...) agrupando a las presunciones de hecho dentro del ámbito de la libre valoración de la prueba, y a las legales, en el de la carga de la prueba.

\footnotetext{
301 PRÜTTING (1983), p. 56.

302 En idéntico sentido: PrütTing (1983), p. 56; Allner (1993), p. 54.

303 LAUMEN en BAUMgärtel et al. (2009), \14, pár. 9; cfr. PrütTing (1983), p. 55.

304 LAUMEN en BAUMGÄRTEL et al. (2009), \ 14, pár. 21.

305 BGH NJW 2010, 363, (364); 2002, 3180 (3181); NJW-RR 2011, 880 (881); 1951, 397; cfr. PrÜtTiNG (1983), pp. 51, 55 s.; LAUMEN en BAUMGÄrTEL et al. (2009), \ 14 pár. 9, 21; PGK, LAUMEN (2011), \ 292 pár. 8; Hk-ZPO, SAENGER (2013), \292, pár. 4; ALLNER (1993), p. 58; MK, PRÜTTING (2013), \292, pár. 27.

306 BGH NJW 1951, 397; cfr. BGH, sentencia de 9. 10. 2009 - V ZR 178/08; KG Berlín (Lexetius.com / 2009, 3249)

${ }^{307}$ BGH NJW 1951, 397; cfr. la nueva jurisprudencia, entre otros: BGH NJW 2002, 3180 (3181); 2010, 363 (364); NJW-RR 2011, 880 (881): PRÜTTING (1983), p. 51.

308 BGH NJW 2010, 363, (364); 1988, 1967; NJW-RR 1988, 1380, 1381, opinión discrepante NJW 1988, 200, 204; cfr. LAUMEN en BAUMGÄRTEL et al. (2009), \ 14, pár. 10, 21; PGK, LAUMEN (2011), \ 292, pár. 8; AlLner (1993), p. 58; Hk-ZPO, SAENGER (2013), \292, pár. 4; WSK, ASSMANN (2012), \292, pár. 13; PRÜTTING (1983), p. 55.

${ }^{309}$ BSGE 19, 52.
} 


\section{e. Las presunciones de hecho como reglas de valoración de la prueba}

Como ya se ha expuesto, resulta necesario distinguir entre las presunciones de hecho o judiciales y las legales. Consecuentemente, la mayor parte de la literatura ${ }^{310}$ ha clasificado a las presunciones de hecho dentro del campo de la libre valoración de la prueba. Lo anterior nos conduce a plantearnos la pregunta sobre la posición que estas detentan dentro del sistema.

\section{i. La presunción de hecho como sinónimo de prueba prima facie}

En la jurisprudencia ${ }^{311}$ y en la literatura ${ }^{312}$ es un lugar común la equiparación conceptual entre presunciones judiciales y prueba prima facie, ya sea por el empleo indistinto de ambos términos, ${ }^{313}$ por medio de la asimilación de los requisitos contemplados para la anulación de los efectos de una y otra, así como en relación con su ámbito de aplicación. En dicho entendido, sería la presunción de hecho solo otra denominación más para la prueba prima facie, que tendría por objetivo generar una reducción en el módulo de prueba exigido.

\section{i.a. Resoluciones judiciales en las cuales se han empleado como sinónimos los conceptos de prueba prima facie y presunción de hecho}

Se ha establecido la existencia de una presunción de hecho respecto de la conducción imprudente de una embarcación, en caso de que dos lanchas se encuentran en un canal, y posteriormente una de ellas al desviarse de su rumbo de navegación impacta a la otra. ${ }^{314}$ De acuerdo con el BGH, el demandante se encuentra - producto de los efectos de esta prueba que denomina prima facieeximido de producir prueba adicional respecto de la responsabilidad del demandado. ${ }^{315}$ La sentencia, en consecuencia, no realiza distinción alguna entre ambas instituciones. ${ }^{316}$

Para establecer la conexión causal entre una infracción a los deberes por parte de un funcionario público y los daños ocasionados posteriormente por este, puede el juez basarse, según sostiene el BGH, en una presunción de hecho, basada en la experiencia bumana, respecto de la causalidad de los daños provocados. ${ }^{317}$

\footnotetext{
310 Entre otros: Rosenberg, SchWAB, GOTTWALd (2010), \113, pár. 36; Hk-ZPO, SAENGER (2013), \292, pár. 4; HEINRICH (1996), p. 99; ALLNER (1993), p. 58; LAUMEN en BAUMGÄRTEL $e t$ al. (2009), 』 14, pár. 21; MUSIELAK (2010), p. 565, s.; PGK, LAUMEN (2011), 』 292, pár. 8.

311 BGHZ 6, 169; 37, 107; BVerwGE 38, 18; OLG Hamm MDR 2006, 1228.

312 Rosenberg (1965), p. 187; WALter (1979), p. 211 s.; JAUERnig y HeSs (2011), \50, pár. 19.

313 Entre otros: JAUERNIG y HeSs (2011), 』50, pár. 19.

314 BGH NJW 1952, 1137; BGHZ 6, 169; 2, 82 (84).

315 BGH NJW 1952, 1137; BGHZ 6, 169; 2, 82 (84); cfr. LAUMEN en BAUMGÄRTEL et al. (2009), \ 14, pár. 2; PRÜTTING (1983), p. 51.

316 En este sentido, vid. AlLNER (1993), p. 36.

${ }^{317}$ BGH NJW 1986, 2829 (2831, s).
} 
Cuando entonces se equiparan conceptualmente o se les dota de igual contenido ${ }^{318}$ se diluye la función de las presunciones de hecho como figura autónoma. ${ }^{319}$

\section{i.b. La presunción de hecho como sinónimo de prueba prima facie en la literatura}

La falta de diferenciación entre la prueba prima facie y la presunción de hecho ha encontrado igualmente un lugar en la literatura. ${ }^{320}$

Walter define la presunción de hecho como una forma de facto de la prueba prima facie, que encuentra su ámbito de aplicación fundamentalmente en el marco del derecho procesal administrativo. ${ }^{321}$ Se trata, sostiene el autor, no de una inversión de la carga de la prueba, sino de una aplicación de los fundamentos de la prueba prima facie, esto es de un fenómeno propio del ámbito de la valoración de la prueba con efecto de reducción del estándar de prueba. ${ }^{322}$ Tras el análisis de la jurisprudencia, Walter llega a la conclusión, de que esta ha equiparado en la práctica ambas instituciones, ${ }^{323}$ concluyendo que, a causa de lo equívoco que este resulta, deberá en lo sucesivo evitarse el empleo del término "presunción de hecho". ${ }^{324}$

La opinión de Walter tiene como fundamento una comprensión amplia de la prueba prima facie. En consecuencia, tal como Rosenberg, ${ }^{325}$ limita Walter el ámbito de aplicación de la prueba prima facie no solo -como históricamente se ha entendido- a la constatación de la culpabilidad y de la causalidad, ${ }^{326}$ extendiéndolo asimismo a la acreditación de elementos constitutivos de un tipo ${ }^{327}$ (como por ejemplo la integridad y veracidad de un documento contractual ${ }^{328}$ ).

\section{ii. La presunción de hecho como elemento constitutivo de una prueba prima facie}

Una opinión similar a la recién expuesta encontramos en la $12^{\mathrm{a}}$ edición del Tratado de Derecho Procesal Civil de Schellhammer, ${ }^{329}$ texto en el que expone su teoría de las

\footnotetext{
318 En este sentido, vid. BGH NJW-RR 1988, 1380.

319 PRÜtTing (1983), p. 57; ALLNER (1993), p. 36.

320 WALTER (1979), pp. 214 s.; WALTER (1977), p. 284. Completamente indiferenciado: JAUERNIG y HESS (2011), \50, pár. 19.

321 WALTER (1979), p. 213.

322 Ibid. pp. 213, s.

${ }^{323}$ Ibid. p. 214.

${ }^{324}$ Ibid.

325 ROSENBERG (1965), p. 187.

326 WALTER (1979), p. 214, s.; WALTER (1977), p. 284.

327 WALTER (1977), p. 279, 284.

328 ROSENBERG (1965), p. 187.

329 SCHELLHAMMER (2007), pár. 519.
} 
presunciones de hecho como elemento constitutivo de la prueba prima facie. Dicho autor es de la opinión de que en el proceso civil la prueba prima facie fundamenta la existencia de una presunción de becho. ${ }^{330}$ Como consecuencia de lo anterior, reconoce como función de esta una simplificación en la actividad probatoria, manifestada en forma de una incompleta y no definitiva inversión de la carga de la prueba y de la alegación a favor de quien se beneficia del efecto de la presunción. ${ }^{331}$ Para la anulación de los efectos de la presunción judicial utiliza Schellhammer dicho concepto indiferentemente del de prueba prima facie. ${ }^{332}$

\section{iii. La presunción de hecho como simplificación probatoria en el marco de la valoración de la prueba}

En ciertas decisiones judiciales ha sido reconocida a la presunción de hecho un efecto de simplificación probatoria en sede de valoración de la prueba, en beneficio de la parte sobre la cual recae la carga de la prueba, sin indicación expresa de los presupuestos que justificarían dicha decisión. ${ }^{333}$

Como ejemplo de lo anterior, podemos sacar a colación una de las más conocidas presunciones de hecho, ${ }^{334}$ la que sostiene que cuando en un contrato bilateral se produce un desequilibrio anómalo entre prestación y contraprestación, puede, en relación con la pregunta sobre el posible atentado a las buenas costumbres de dicho contrato, aceptarse por medio de una presunción de hecho la existencia de un accionar reprobable por parte de uno de los contratantes. ${ }^{335}$ Dicha presunción tendría su fundamento en que por regla general no se llevan a cabo prestaciones excesivas y extraordinarias sin la presencia de una situación de emergencia, $u$ otros obstáculos por parte de la parte perjudicada. ${ }^{336}$ En estos casos, deduce el BGH la existencia de una presunción de hecho como elemento simplificador de la prueba, que debe ser considerada por el juez, en el marco de la valoración de la prueba. ${ }^{337}$

\footnotetext{
330 Ibid.; OLG Hamm MDR 2006, 1228; BGH NJW-RR 2003, 1071.

331 SCHELLHAMMER (2007), pár. 519.

332 Ibid.

333 PRÜTTING (1983), p. 56; ALLNER (1993), p. 37.

334 Sobre esta presunción de hecho, cfr. MUSIELAK (2010), ebenda.

335 BGH, sentencia de 9. 10. 2009 - V ZR 178/08; KG Berlin (Lexetius.com / 2009, 3249); cfr. LAUMEN en BAUMGÄRTEL et al. (2009), \14, pár. 2, nota al pie 27, ss.; BGH NJW 1986, 2564, 2565; 1988, 1659, 1661; sobre un empleo contrario a las buenas costumbres de la providencia de ejecución, vid. OLG Düsseldorf NJW-RR 1987, 938, 940; sobre el contrato de leasing inmobiliario, vid. BGH NJW 1995, 1019; sobre el contrato de corretaje, vid. BGH NJW 1994, 1475, sobre la transferencia de propiedad vid. BGH NJW 2001, 1127, 1128 s.; 2002, 3165; BGH NJW-RR 2006, 1677.

336 BGH NJW 2001, 1127, 1128 s.

337 BGH NJW 2001, 1127, 1128 s.; 2010, 363.
} 
La antigua jurisprudencia sobre este caso ${ }^{338}$ permitía la acreditación sin más del requisito subjetivo contemplado en el $\ 138$ inc. $1^{\circ}$ BGB para configurar la ilicitud del contrato, únicamente basado en el accionar reprochable derivado del desequilibrio anómalo entre prestación y contraprestación.

Por el contrario, según una nueva decisión del $\mathrm{BGH},{ }^{339}$ la parte beneficiada con la presunción debe acreditar la concurrencia del elemento subjetivo de una situación equiparable a la lesión enorme. Siguiendo dicha postura, cumplirían las presunciones de hecho solo una función de apoyo en relación con la vulneración a la equivalencia de las prestaciones en favor de la parte perjudicada con la relación contractual, en su exposición sobre los requisitos subjetivos de la situación equiparable a la lesión enorme derivada de un negocio jurídico. ${ }^{340}$ Creemos que solo dicha interpretación es compatible con su función dentro de la valoración de la prueba. ${ }^{341}$

De acuerdo con esta nueva jurisprudencia sobre la presunción de hecho recaída en un notorio desequilibrio de las prestaciones, ${ }^{342}$ que el BGH correctamente ha incluido dentro del campo de la libre valoración de la prueba, debe acreditarlo plenamente la parte que alega el elemento subjetivo del tipo equiparable a la lesión enorme (accionar reprobable). Esta parte en consecuencia ( $\mathrm{y}$ al contrario de lo que sucede con las presunciones legales) no se encuentra liberada de la carga de alegación de dicha circunstancia. ${ }^{343}$

Los alcances de esta presunción resultan asimismo aplicables en el campo del derecho del consumidor: cuando concurre el tipo objetivo de una lesión enorme referida a un crédito de consumo, se presumirán los requisitos subjetivos del $\int 138$ I BGB. ${ }^{344}$

Igualmente, en casos de existencia de una exigencia financiera excesiva sobre el cónyuge o pariente cercano de quien ha contratado para sí un préstamo, se establece la existencia de una presunción de hecho respecto de que el cónyuge o pariente cercano, al momento de constituirse en codeudor no actuaron de acuerdo a sus intereses, ni de conformidad a un análisis racional de los riesgos económicos, con lo que la institución crediticia ha utilizado de manera contraria a las buenas costumbres la relación emocional entre el deudor principal y el codeudor. ${ }^{345}$

\footnotetext{
338 BGH NJW 2001, 1127, 1128 s.; 1986, 2564; 1988, 1659; 1988, 130, 131; 1994, 1475; 2000, 2352, 2353; 2000, 2669, 2670; 1981, 1206, 1207; 2002, 55, 57; NJW-RR 1993, 198; cfr. MUSIELAK (2007), $\int 1$, pár. 15.

339 BGH NJW 2010, 363; cfr. MusieLAK (2010), p. 561.

340 BGH NJW 2010, 363.

341 MuSiELAK (2010), p. 561.

342 BGH NJW 2010, 363.

343 MUSIELAK (2010), p. 561.

344 BGH NJW 1988, 1659.

345 BGH NJW 2001, 815; cfr. BGH NJW 2002, 744 (745); BGH NJW 2004, 161, 162; contra: MUSIELAK (2010), pp. 561 ss.; LAUMEN en BAUMGÄRTEL et al. (2009), \ 14, pár. 2.
} 
La clasificación de las presunciones de hecho como reglas aplicables en sede de valoración de la prueba resulta correcta como punto de partida. Sin embargo, en contra de la clasificación indiferenciada de las presunciones de hecho como categoría autónoma en el marco de la valoración de la prueba, al no existir certeza de los criterios que permitirían distinguirla de instituciones afines, existe incertidumbre respecto de los efectos concretos que dichas presunciones generarían. ${ }^{346}$

\section{iv. Las presunciones de hecho como prueba prima facie o prueba de indicios, dependiendo de su intensidad}

Como instrumento aplicable en el marco de la libre valoración de la prueba, una parte importante de la doctrina ${ }^{347}$ ha clasificado a las presunciones de hecho de acuerdo con el alcance de sus efectos. ${ }^{348}$ En esta línea encontramos entre otros a Prütting, ${ }^{349}$ Baumgärtel ${ }^{350}$ y Laumen, ${ }^{351}$ quienes tras un análisis de la jurisprudencia recaída en las presunciones de hecho llegan a la conclusión que esta figura puede considerarse tanto como elemento constitutivo de prueba prima facie ${ }^{352} \mathrm{o}$ bien de prueba de indicios, ${ }^{353}$ según sea su intensidad.

De igual modo, en una nueva decisión del $\mathrm{BGH}^{354}$ puede leerse que una presunción de becho solo encuentra significado en el campo de la valoración de la prueba, cuando esta fundamenta una prueba prima facie o de indicios respecto del hecho controvertido. Por su parte, el BSG ha señalado en este sentido que las presunciones de hecho se basan en experiencias humanas, que por medio de la libre valoración de la prueba permiten obtener conclusiones o elementos probatorios que permiten hacer innecesaria una producción adicional de prueba, o bien, cuando su fuerza probatoria no sea suficiente para ello, ser consideradas junto a otros elementos en la valoración judicial. 355

Así, en los casos en que nos encontremos frente a una experiencia humana calificada como especialmente intensa, resulta posible -de acuerdo con esta teoría-

\footnotetext{
346 PRÜTTING (1983), p. 57.

347 LAUMEN en BAUMGÄRTEL et al. (2009), \ 14, pár. 13; SJK, LEIPOLD (2008), 』 292, pár. 7; MK, PRÜtTiNG (2013), \292, pár. 28; (1983), p. 56 s.; HEINRICH (1996), p. 99; PGK, LAUMEN (2011), \ 292, pár. 8; Hk-ZPO, SAENGER (2013), \292, pár. 4.

348 BGH, sentencia de 9. 10. 2009 - V ZR 178/08; KG Berlin (Lexetius.com/ 2009, 3249); LAUMEN en BAUMGÄrTEL et al. (2009), \14, pár. 2; MK, PRÜTTING (2013), \292, pár. 28; PGK, LAUMEN (2011), \292, pár. 8.

349 PRÜTTING (1983), p. 58.

350 BAUMGÄRTEL (1990), p. 51.

351 LAUMEN en BAUMGÄrTEL et al. (2009), 』14, pár. 21; PGK, LAUMEN (2011), 』 292, pár. 8.

352 Por ejemplo: BGH MDR 1986, 31; OLG Köln NJW-RR 2004, 1151.

353 Por ejemplo: OLG Hamm NJW 1974, 1827; BGHZ 53, 260, s.

354 BGH NJW 2010, 363.

355 BSGE 19, 52, 54; ALLNER (1993), p. 38.
} 
reconducir una presunción de hecho a una prueba prima facie. ${ }^{356}$ En estas hipótesis entrarán en consideración las reglas sobre la prueba prima facie que posibilitan una inversión de la carga subjetiva de argumentación, de modo que la prueba principal recaida en un hecho controvertido podrá tenerse por acreditada, recayendo en la parte contraria la refutación de este, por medio de la contraprueba, ${ }^{357}$ señala Laumen.

Cuando por el contrario, la experiencia humana que fundamenta la presunción de hecho no resulta suficientemente intensa para que el tribunal tenga por acreditado un hecho, se producirá su valoración conjunta con otros elementos probatorios, por medio de la prueba de indicios. ${ }^{358}$ Se trataría en estos casos de situaciones en las que la experiencia de vida, base de la presunción, no resulta suficiente para justificar una prueba prima facie. De este modo ha sido muchas veces clasificada esta especie de presunción de hecho "de efectos incompletos"359 como una prueba prima facie de menor grado. En su sentencia del 21.12.1960 estableció el BGH a este respecto que existen reglas de la experiencia que resultan tan vinculantes, que en el ámbito de la prueba prima facie pueden otorgar la plena prueba respecto del suceso controvertido, aun bien conferir una menor probabilidad respecto de la ocurrencia de un becho controvertido. Incluso aquellas reglas de la experiencia, que no resultan suficientes para fundamentar una prueba prima facie, pueden (...) cobrar relevancia en sede de valoración de la prueba. $^{360}$

Un indicio por sí solo no permite concluir justificadamente sobre la existencia o inexistencia de un hecho controvertido. ${ }^{361}$ Por ello, una presunción de becho de menor grado no podrá satisfacer el estándar de convicción judicial para tener un hecho por acreditado, ${ }^{362}$ sino únicamente lograrlo en valoración conjunta con otros indicios.

Como tercera categoría menciona Laumen aquellas presunciones de hecho que no resulta posible encasillar ni como prueba prima facie ni como prueba de indicios, sino como meros prejuicios. ${ }^{363}$ En estos casos no se puede invocar como su fundamento las reglas de la experiencia humana, sino que por el contrario, se trataría de meras afirmaciones carentes de relevancia jurídica. Como ejemplo

\footnotetext{
356 OLG Hamm MDR 2006, 1228; BGH NJW 1994, 3295 (3298); 1998, 749 (750); cfr. LAUMEN en BAUMGÄrTEL et al. (2009), \14, pár. 13; PGK, LAUMEN (2011), \292, pár. 8; BAUMGÄrTEL (1990), p. 50; PRÜTTING (1983), p. 58.

${ }^{357}$ LAUMEN en BAUMGÄrTEL et al. (2009), 』 14, pár. 17.

358 BGH NJW 1951, 397; OLG Hamm NJW 1974, 1827, 1828; cfr. LAUMEN en BAUMGÄRTEL et al. (2009), 』 14, pár. 18 s.; BAUMgäRtel (1990), p. 50; PrÜtTing (1983), p. 58; MK, PRÜTting (2013), \ 292 pár. 28; HEINRICH (1996), p. 99.

359 BGH NJW 1961, 777; cfr. PRÜTTING (1983), p. 56.

${ }^{360}$ BGH NJW 1961, 777.

361 ANZINGER (2006), pp. 73, s., 34, s.

362 PrÜtTiNG (1983), p. 57; PGK, LAUMEN (2011), \292, pár. 8; BAUMGÄRTEL (1990), p. 50.

363 LAUMEN en BAUMGÄRTEL et al. (2009), \14, pár. 20.
} 
señala el autor la presunción de hecho que señala que todo lo que se traga, debe ser considerado alimento. ${ }^{364}$

Independiente de su ordenación como prueba prima facie o como prueba de indicios es -de acuerdo con esta postura- relevante para la determinación de los efectos de una presunción de hecho que el juez en su decisión exponga claramente en cuál de las referidas categorías ha aplicado la presunción de la que se vale. ${ }^{365}$

En resumidas cuentas, debido a que en los casos en que la presunción de hecho se basa en la presencia de una regla de la experiencia especialmente intensa, corresponde esta a una prueba prima facie. Por otro lado, en los casos en que la presunción se encasilla dentro del amplio espectro de la prueba de indicios tampoco se justificaría le existencia de una presunción de becho de menor nivel, perdiendo así esta significado y relevancia jurídica como categoría autónoma. ${ }^{366} \mathrm{En}$ virtud de lo anterior, abogan dichos autores por la supresión definitiva del concepto de presunción de hecho. ${ }^{367}$

\section{v. La teoría de las presunciones de hecho como presunción basada en un antejuicio}

Los indicios como elementos probatorios se utilizan para la acreditación de hechos que no pueden comúnmente ser - de acuerdo con la terminología tradicionaldirectamente probados, sino solo lo son por medio de elementos ajenos, llamados hechos complementarios. Por medio de estos hechos complementarios se puede derivar la existencia de una presunción de hecho que permite acreditar la existencia de un presupuesto propio de un tipo legal determinado. ${ }^{368}$

De acuerdo con Allner, el empleo por parte de los jueces de estos indicios se produce en un doble sentido: como conclusión individual derivada de un caso concreto, y además respecto de decisiones, en las cuales la controversia jurídica planteada ya fue resuelta previamente en casos anteriores (antejuicio). ${ }^{369} \mathrm{En}$ ambos casos debe el juez desde luego estar convencido de la veracidad de los indicios empleados, de forma que estos puedan constituir el fundamento de la decisión a adoptar. ${ }^{370}$

En la primera de las hipótesis señaladas se emplean indicios derivados de conocimientos obtenidos en el caso concreto, por ejemplo las conclusiones

\footnotetext{
${ }^{364}$ Ibid.

365 Ibid. pár. 21.

366 Prütting (1983), p. 58; LAUMEN en BAUMgärTel et al. (2009), \14, pár. 21; BAUMgÄrTeL (1990), p. 51; ZÖLLER, GREGER (2010), @ 284, pár. 33.

367 PrütTing (1983), p. 58; LAUMEN en BAUMGÄrtel et al. (2009), \14, pár. 21; ZÖLLer, GREGER (2010), \284, pár. 33.

368 DÄNZER (1914), p. 11; AlLNER (1993), p. 59.

369 ALLNER (1993), p. 60, ss.

370 Ibid. p. 59.
} 
obtenidas de un análisis de sangre. ${ }^{371}$ Estas conclusiones individuales se utilizan, de acuerdo con Allner tanto para las presunciones de hecho, como para la prueba de indicios. Asi, resulta igual que el tribunal, por medio del análisis de hechos expuestos ajenos al tipo cuyos elementos se pretenden acreditar, tenga por acreditada una prueba de indicios o una presunción de becho. ${ }^{372}$

Debido a que en estas situaciones el tribunal adquiere el convencimiento del hecho invocado por medio de una prueba indirecta (como lo es la prueba de indicios), la distinción entre ambos instrumentos se fundamentaría, sostiene Allner, exclusivamente en la arbitraria praxis judicial, que muchas veces ante situaciones idénticas decide por medio de una presunción de hecho invertir la carga de la prueba sin fundamento para ello. ${ }^{373}$ Concluye dicha autora rechazando esta variante de las presunciones de hecho debido a que se fundamenta exclusivamente en una arbitraria distinción respecto de la prueba de indicios. ${ }^{374}$

En la segunda constelación de casos, los llamados antejuicios, la base de la presunción de hecho se funda en decisiones jurídicas anteriores. Allner ${ }^{375}$ afirma a este respecto que la presunción de hecho se obtiene de una comprobada máxima de la experiencia obtenida por medio de un proceso de inducción derivado del conocimiento de la jurisprudencia asentada, la cual para su modificación o anulación requerirá del empleo de una contraprueba. En este sentido señala ${ }^{376}$ que los conocimientos que otorga la jurisprudencia asentada (antejuicios) permiten construir el fundamento o base de la presunción, en el sentido que los fundamentos considerados por la decisión previa, subyacente a la decisión de un conflicto, se presentan de igual forma en el caso concreto.

Para esclarecer la teoría de las presunciones judiciales aboga por reemplazar el concepto de presunción de hecho por el de presunción basada en un antejuicio. $^{377}$

En similar sentido, define Dänzer las presunciones de hecho como reglas, por medio de las cuales un hecho a probar, por medio de la aplicación de una regla de la experiencia, se tendrá por acreditado hasta su eventual refutación por medio de la contraprueba. La aplicación de dicha regla se produce por medio de la inducción de un hecho diverso al hecho a probar. ${ }^{378} \mathrm{El}$ autor reconoce como fundamento de estas presunciones la aplicación de conclusiones idénticas entre sí, obtenidas de una serie de casos similares al que se juzga ${ }^{379}$ Por ello, sostiene Dänzer, se produce de una presunción concreta, una generalidad, una presunción de

\footnotetext{
${ }^{371}$ Ibid. p. 60.

372 Ibid.

373 Ibid.

374 Ibid.

375 Ibid. p. 124.

376 Ibid.

377 Ibid. p. 125.

${ }^{378}$ DÄNZER (1914), p. 1.

${ }^{379}$ Ibid. p. 12.
} 
Correa - La presunción de hecho como figura jurídica en el derecho procesal civil alemán

hecho en sentido técnico, en la cual esta se abstrae del caso concreto, pasando a constituir, sin más, una regla de solución aplicable a una serie de casos idénticos. ${ }^{380}$

\section{Hacia una adecuada concepción de las presunciones de hecho}

Habiendo ya demostrado que las presunciones judiciales desempeñan su papel en el ámbito de la valoración de la prueba, debemos determinar su relación respecto de la prueba de indicios y a la prueba prima facie para, tras ello, formular un concepto adecuado de presunción de hecho que permita sortear las dificultades ya expuestas por la doctrina.

\section{a. La presunción de hecho de menor grado como prueba de indicios: un concepto innecesario}

Como ya se expuso, para un sector preponderante de la doctrina aquellas reglas de la experiencia humana que no son capaces por sí solas de satisfacer el estándar de prueba pueden solo jugar un papel como indicios. ${ }^{381}$ Las presunciones de hecho que se asimilan a esta categoría no pertenecerían, debido a su innecesario concepto, a ninguna categoría autónoma. ${ }^{382}$

Dicha crítica es correcta. El ámbito de aplicación de la prueba de indicios, a diferencia del concerniente a la prueba prima facie, no se encuentra históricamente limitado a la prueba de la causalidad y de la culpabilidad. Por el contrario, mediante la prueba de indicios podemos dar por acreditado cualquier asunto susceptible de actividad probatoria, independiente de su objeto.

Cuando las reglas de la experiencia solo permiten tener por acreditados hechos discutidos en conjunto con otros indicios, la denominación de dichas reglas de la experiencia como presunciones de hecho carece de sentido. Su empleo diferenciado derivará entonces en hipótesis inadmisibles, en las que es posible constatar una vulneración de las reglas objetivas de distribución de la carga de la prueba, generadas a partir del uso indebido de esta herramienta por parte de los tribunales.

\section{b. El rechazo de la comprensión de presunciones de hecho como antejuicios}

Existen poderosos fundamentos que permiten desestimar la comprensión de presunciones de hecho como antejuicios. Como se señaló supra, por medio del empleo de reglas de la experiencia analizan los jueces la concurrencia de hechos

\footnotetext{
380 Ibid.

381 BAUMGÄRTEL (1990), pp. 50 ss.

382 PRÜtTiNG (1983), p. 58; LAUMEN en BAUMGÄrTEL et al. (2009), \14, pár. 21; BAUMGÄrTEL

(1990), p. 51; ZÖLLER, GREGER (2010), \284, pár. 33; ALLNER (1993), p. 60.
} 
pasados, que por medio de un proceso lógico de carácter inductivo permiten formular una adecuada prognosis respecto de situaciones similares de actual ocurrencia. Ellas permiten al juez, bajo ciertos requisitos, alcanzar el nivel de certeza necesario, para tener por acreditado un hecho controvertido.

Pese a que la comprobación por medio de una multiplicidad de fallos otorga una gran certeza respecto de la concurrencia del presupuesto tipicidad de una determinada regla de la experiencia, ${ }^{383}$ la diferencia existente entre los distintos casos, y sus características especiales impide su generalización pura y simple, carente de excepciones.

Por el contrario, para establecer el objeto de la presunción de hecho debe el juez acreditar en el caso concreto la concurrencia de una regla de la experiencia, independiente de si ella ha sido con antelación aplicada a casos similares de resolución previa. El juez no se encuentra autorizado a tomar como ciertas sin más las conclusiones derivadas del análisis de casos anteriores, traspasándolas al caso puntual; debe señalar de modo expreso en cada decisión judicial las razones por las cuales las conclusiones adoptadas en casos anteriores resultarían aplicables al caso concreto.

La mera intención de estandarizar la jurisprudencia no alcanza para alcanzar el estándar de prueba suficiente. Por el contrario, en cada decisión deberá el juez ponderar libremente la concurrencia de reglas de la experiencia así como su alcance. Una serie de decisiones jurisdiccionales no constituyen entonces per se un criterio para determinar la existencia de una presunción de hecho.

En este sentido, debemos rechazar la teoría sostenida por Allner y Dänzer, que fundamenta la presunción de hecho en una "jurisprudencia unánime". Por el contrario, la existencia de jurisprudencia unánime sobre un tema específico corresponde más bien a una confirmación de la idoneidad de una regla de la experiencia para generar el convencimiento judicial, empero no su fundamento. ${ }^{384}$

\section{c. Delimitación entre prueba prima facie y presunción de hecho}

Como se indicó, la presunción de hecho de menor grado corresponde en definitiva a una prueba de indicio, siendo superfluo su empleo como categoría autónoma. Tampoco resulta posible desprender el fundamento de las presunciones de hecho en antejuicios. Por ello, debemos investigar si las presunciones judiciales tienen un lugar dentro de la teoría de la prueba prima facie, y en caso afirmativo, qué diferencias existen entre ellas.

\footnotetext{
383 ALLNER (1993), p. 71.

384 Cfr. MusielaK (2010), p. 563.
} 
La diferencia -como lo ha destacado parte de la literatura- radica en el objeto de la prueba. ${ }^{385}$ Mientras, como se señaló previamente, la prueba prima facie se relaciona -por razones históricas- con la acreditación de la causalidad y la culpabilidad, es objeto de la presunción judicial la acreditación de un hecho controvertido, distinto de las categorías propias de la prueba prima facie. ${ }^{386}$ Por ejemplo, la presunción de hecho sobre la exactitud de la fecha escrita en un documento privado recae precisamente en la acreditación de un elemento fáctico propio del contrato cuya veracidad se pretende probar, ajeno a la causalidad y la culpabilidad, y cuyos efectos abarcan tanto el ámbito de la responsabilidad contractual como extracontractual. Lo mismo sucede respecto de la presunción de hecho recaída en la integridad de un contrato, donde el hecho objeto de la presunción corresponde precisamente a un elemento destinado a acreditar la vigencia de estipulaciones contractuales, elemento ajeno y en muchos casos anterior al objeto de la prueba prima facie.

Así, la constatación de una presunción de hecho para acreditar la causalidad o la culpabilidad, respetando su ubicación sistemática, no sería -por razones de índole histórica- posible. ${ }^{387}$

La opinión de Schellhammer, de la prueba prima facie como fundamento de una presunción de becho, como la teoría de Walters de una forma de facto de la prueba prima facie, así como la postura sostenida por Prütting, Baumgärtel y Laumen, entre otros, por medio de la cual la presunción de hecho podría justificar a causa de su intensidad una prueba prima facie, desconocen la diferencia esencial entre estas, referida a su ámbito de aplicación: la prueba prima facie no resulta idónea para acreditar la existencia de hechos distintos de los que determinan la causalidad y la culpabilidad.

\section{d. Las máximas de la experiencia como punto de partida de las presunciones de hecho}

Como sucede respecto de la prueba prima facie, acerca de las presunciones de hecho encontramos su punto de partida no en un precepto legal determinado, sino en reglas de la experiencia, ${ }^{388}$ fundamentadas en la experiencia humana. ${ }^{389}$ Como

\footnotetext{
385 WSK, ASSMANN (2012), \292, pár. 13; ALLNER (1993), p. 63.

386 AlLNer (1993), pp. 63, 65; LAUMEN en BAUMGÄRTEL et al. (2009), \14, pár. 5; BAUMGÄRTEL (1990), p. 44; WSK, ASSMANN (2012), \292, pár. 13.

387 Opinión discrepante BGH NJW 1986, 2829 (2831, s.); OLG Hamm MDR 2006, 1228; cfr. AlLNER (1993), p. 63; BAUMGÄRTEL (1990), p. 44.

388 BGH NJW 2010, 363; 1988, 258, 259; 1986, 2829, 2831; 1961, 777; 1951, 397; 1966, 826; BVerwG, sentencia de 25.6.2008 - 8 C 12. 07 (Lexetius.com/ 2008, 2278); cfr. MusielaK (2012b), pár. 480; MUSIELAK, HUBER (2012a), \ 292, pár. 1.

389 BGH, sentencia de 5.3.2004 - 28/04 (Lexetius.com/ 2004, 218 [2004/3/265]); BGH, Urteil vom 2. 3. 2009 - II ZR 266/07 (Lexetius.com/ 2009, 497); BVerwG, sentencia de 25.6.2008 - 8 C 12. 07 (Lexetius.com/ 2008, 2278); BVerwGE 17, 141 (143);BGH NJW 1951, 397; BGH NJW 2002,
} 
Dänzer ya en 1914 estableció, la presunción de derecho encuentra su fundamento en un precepto legal, la de hecho en una regla de la experiencia. ${ }^{390}$

Como se señaló, el campo de aplicación de las presunciones de hecho se limita (atendida su diferencia referente a la prueba de indicios), como sucede respecto de la prueba prima facie, a casos en los cuales una regla de la experiencia es por sí sola adecuada para acreditar un hecho controvertido.

La idoneidad de una presunción de hecho para generar el razonamiento judicial se genera por medio de un complejo proceso de conocimiento y comprensión del mundo, el que, según sostiene Musielak sucede por la observación del curso de los hechos que presentan elementos coincidentes, los cuales, producto del resultado de dicha observación, permiten conchir la relativa frecuencia con que ciertos fenómenos se llevan a cabo. ${ }^{391}$

Como sucede con relación a la prueba prima facie, pueden las máximas de la experiencia por sí, e independientemente de otros elementos, y de decisiones judiciales previas, permitir el establecimiento de hechos en el proceso civil. ${ }^{392}$ Estas serán en consecuencia tanto el punto de partida como la escala adecuada para la aplicación de presunciones judiciales. ${ }^{393}$

Conforme con el BVerwG, las presunciones de hecho tienen por base acontecimientos, que transcurren típicamente del mismo modo. El carácter típico de un curso de becho se demuestra a su vez, a través de la experiencia bumana general. ${ }^{394} \mathrm{La}$ tipicidad de la experiencia humana (elemento central de las máximas de la experiencia) confiere al juez (de acuerdo a su vinculación con estas y con las reglas de la lógica) seguridad referente a la acreditación de hechos.

Para la determinación de la existencia de una presunción judicial se aplica el mismo proceso inductivo, propio de las ciencias naturales. ${ }^{395}$ En efecto, cuando la decisión de un órgano jurisdiccional se fundamenta en una máxima de la experiencia, puede equipararse a esta en atención a la objetividad y exactitud de la misma con los resultados de carácter científico. ${ }^{396}$ Por medio de esta operación resulta posible describir de un modo general prácticamente cualquier suceso individual cuya plausibilidad no resulte controvertida. ${ }^{397}$

3180 (3181); 2010, 363 (364); NJW-RR 2011, 880 (881) cfr. PrÜTTING (1983), p. 51; Musielak (2010), p. 565.

390 DÄNZER (1914), p. 1.

391 MusieLAK (2010), p. 563.

392 BFH, sentencia de 28.1.1992 - VIII R 7/88; FG Nürnberg (Lexetius.com/ 1992, 548)

393 En el mismo sentido: WSK, AssmanN (2012), \292, pár. 13.

${ }^{394}$ BVerwG, sentencia de 25.6.2008 - 8 C 12. 07; VG Frankfurt (Lexetius.com/ 2008, 2278)

395 MUSIELAK (2010), p. 563.

396 Ibid.

397 Musielak, Foerste (2012a), 』286, pár. 23. 
Cuando el juez establece que una regla de la experiencia resulta adecuada para tener por acreditado un hecho controvertido, no deviene dicha constatación, como pretenden Allner y Dänzer, de la aplicación de una decisión judicial previa, sino en realidad de un complejo proceso inductivo, donde gracias a la experiencia humana se posibilita la averiguación de hechos.

Lo anteriormente formulado podría llevar a sostener que este proceso correspondería a uno de carácter subjetivo e individual. Muy por el contrario, este tiene su origen en reglas acreditables basadas en la experiencia por parte de cualquier observador externo. En virtud de ello, se ha sostenido que ${ }^{398}$ quien acumula experiencia y la aplica, actúa a pesar de toda subjetividad, objetivamente. Los resultados de sus comprobaciones no se encuentran entonces en su mera voluntad.

A causa de que las consecuencias de las presunciones de hecho, a diferencia de lo que ocurre con las presunciones legales, no se encuentran en la ley, la parte beneficiada en primer término deberá invocar un precepto jurídico cuya acreditación se apoya en una presunción de hecho. ${ }^{399}$ La parte que, como acontece con la prueba prima facie, aduce la aplicación de una presunción de hecho deberá exponer los presupuestos materiales en que dicha presunción se funda y, de acuerdo con las reglas generales, probarlo plenamente.

\section{e. La presunción de hecho respecto de la existencia o mantenimiento de una voluntad interna}

Especialmente problemática resulta la aplicación de una presunción de hecho respecto de casos en los cuales se discute la existencia o el mantenimiento de una voluntad interna. ${ }^{400}$

En efecto, respecto de hechos de naturaleza interna resulta difícil acceder a prueba directa. Por el contrario, estos suelen normalmente ser acreditados casi exclusivamente por medio de hechos externos, que permitan concluir la presencia de un determinado móvil de carácter subjetivo. ${ }^{401}$

En distintos fallos ha resuelto la jurisprudencia sobre la concurrencia de elementos subjetivos de un tipo jurídico por medio de presunciones de hecho. ${ }^{402}$

En el ya mencionado caso de la presunción de hecho referida al elemento subjetivo del contrato de préstamo de dinero contrario a las buenas costumbres, ha utilizado la jurisprudencia la presunción de hecho para acreditar los motivos internos de la institución crediticia, que configuran el elemento subjetivo del tipo

\footnotetext{
398 MuSiELAK (2010), p. 563.

399 Ibid. p. 564.

400 BAUMgärTEL (1990), p. 50; Allner (1993), p. 47.

401 ALLNER (1993), p. 47.

402 Ibid.
} 
de negocio jurídico equiparable a la lesión enorme. ${ }^{403}$ En este sentido, la jurisprudencia ${ }^{404}$ ha señalado por medio del empleo de reglas de la experiencia que por regla general, contraprestaciones inusualmente elevadas no se acuerdan sin la existencia de una necesidad que aflige a uno de los contratantes, acreditando con ello el elemento subjetivo del tipo, consistente en el modo de actuar reprochable. ${ }^{405}$

Asimismo, en los casos de un acuerdo al momento de la entrega de una cosa se presume de hecho la duración a posteriori de la voluntad interna de entrega. ${ }^{406}$

Pese a que el ámbito de aplicación de las presunciones de hecho no se limita a la comprobación de la causalidad y de la culpabilidad (como sucede respecto de la prueba prima facie), no resulta posible tener por acreditada una voluntad interna por medio de máximas de la experiencia. ${ }^{407}$ En efecto, atendido los factores de incertidumbre que genera el análisis de la individualidad, ${ }^{408}$ y su naturaleza irrepetible, que impiden dotar de tipicidad al hecho a acreditar, su comprobación por medio de reglas de la experiencia dotadas de vigencia general, resultará imposible.

De lo que se trata en estos casos es de la aplicación de una presunción de becho de menor intensidad, que como ya se explicó puede ser subsumida dentro de la prueba de indicios.

\section{f. La refutación de la presunción de hecho}

La investigación desarrollada permite inferir que la pregunta sobre si para privar de efectos a una presunción de hecho es necesaria la prueba de lo contrario ${ }^{409}$ o la contraprueba, ${ }^{410}$ resulta controvertida. Los tribunales se han inclinado de manera vacilante ante ambas posiciones, incluso respecto de casos similares.

La jurisprudencia constante referida a la presunción de hecho sobre la integridad y veracidad de la fecha escrita de un documento privado ha señalado que por medio de esta se invierte la carga objetiva de la prueba, de modo que el

\footnotetext{
403 Ibid.; ANZINGER (2006), p. 35; BAUMGÄRTEL (1990), p. 44 s.

404 BGH NJW 1988, 130, 131.

405 Contra: MusielaK (2010), p. 561; Allner (1993), p. 47.

406 BGH WM 1960, 1223 (1227); 1965, 1248; 1977, 218, (219); cfr. BAUMGÄRTEL (1990), p. 50; LAUMEN en BAUMGÄRTEL et al. (2009), \14, pár. 15.

${ }^{407}$ LEPA (1992), p. 130.

408 ALLNER (1993), p. 49.

${ }^{409}$ BGH NJW 2002, 3164, 3165; 1980, 1680 (1681); 2008, 2852, (2853); 1987, 2012 (2014); 1999, 1702; 2000, 207; 1970, 1187; 1956, 665; en la literatura: WASSERMEYER (1954), pp. 34, ss.

${ }^{410}$ BGH NJW 2000, 1179, 1181; 1988, 1967; BGH MDR 1986, 31; OLG Köln MDR 1972, 865; OLG Köln NJW-RR 2004, 115; en la literatura: AlLnER (1993), p. 40; MK, PRÜTTING (2013), 』 292, pár. 27, s.; MUSIELAK (2010), p. 561, ss.; LAUMEN en BAUMGÄRTEL et al. (2009), \14, pár. 13; BAUMGÄRTEL (1990), p. 42, 48, s.
} 
juez requerirá de la prueba de lo contrario para privarla de efectos. ${ }^{411}$ Raramente se exigirá en este caso por parte del juez una mera contraprueba. ${ }^{412}$

En los casos en que una presunción de hecho conduce a una inversión de la carga de la prueba, podrán rebatirse sus efectos - de manera análoga a lo que sucede respecto de las presunciones legales- exclusivamente por medio de la prueba de lo contrario. Sin embargo, cuando se exige esta prueba de lo contrario para privar de efectos a una presunción de hecho, se olvida que el objetivo perseguido por la prueba de refutación no es convencer al juez de la inexactitud de la regla de la experiencia aplicada, sino por el contrario, cuestionar el convencimiento del tribunal sobre la existencia efectiva de un hecho controvertido. ${ }^{413}$

En atención al rebatimiento de una presunción de hecho como consecuencia de su clasificación como regla de valoración de la prueba, debe el juez de conformidad a lo dispuesto en el $\$ 286$ probar si la regla de la experiencia resulta o no aplicable. Por ello, puede el tribunal por medio de la refutación de la aplicabilidad de la máxima de la experiencia, en el caso concreto, impedir la aplicación de la presunción de hecho. Esto sucederá por medio de una contraprueba, de acuerdo con las reglas de refutación de la prueba prima facie, ya analizadas. ${ }^{414} \mathrm{La}$ contraparte deberá por medio de esta contraprueba exponer y acreditar que la regla de la experiencia (a causa de la posibilidad cierta de un suceso atípico o de otro curso de los acontecimientos) no resulta aplicable al caso concreto.

Por ejemplo, en el tantas veces citado caso de la presunción de hecho sobre la fecha establecida en un instrumento privado, cuando se exige la contraprueba para privar de efectos a la presunción significa esto que la contraparte deberá exponer y acreditar que no resulta posible tener por fecha del contrato la allí señalada, porque por ejemplo en esa fecha se encontraba en el hospital. ${ }^{415}$ Cuando en contraposición a ello se exige la plena prueba de lo contrario, que obligaría a la contraparte exponer y probar la fecha exacta en la que se habría celebrado el contrato, conllevaría ello, como acertadamente señala Allner, a un perjuicio para todas las personas sin experiencia en el campo de los negocios, ${ }^{416}$ no resultando así un criterio razonable. ${ }^{417}$

${ }^{411}$ KG MDR 1977, 674; BGH NJW 1980, 1680, 1681; 1956, 665; cfr. PRÜTTING (1983), p. 55; LAUMEN en BAUMGÄRTEL et al. (2009), \14, pár. 2; WSK, ASSMANN (2012), \292, pár. 14.

412 NJW-RR 2003, 384, s; 2000, 1179, 1181; cfr. ASSMANN \ 292 (2012), pár. 16.

413 ALLNER (1993), p. 57.

414 BVerwG, sentencia de 16.5.2012 - 5 C 2. 11 (Lexetius.com/ 2012, 3620); sentencia de 26.02.2009 - BVerwG 5 C 4. 08; cfr. BAumgärtel (1990), p. 48; Allner (1993), p. 73, 88; WSK, ASSMANN (2012), \$292, pár. 14.

415 AlLNER (1993), p. 46.

416 Ibid.

${ }^{417}$ Ibid. p. 57. 
En el caso de la presunción referida al corredor de propiedades, debe el contratante refutar la pretendida actividad del corredor como fundamento de la celebración del contrato mediante la exposición y prueba de un conocimiento de la propiedad objeto del contrato, previo a la actividad del corredor (contraprueba). ${ }^{418}$ No resultará entonces necesario rendir la plena prueba de lo contrario, consistente en que el contrato se celebró con absoluta independencia de la actividad del corredor.

\section{Conclusiones}

De la investigación antecedente resulta preciso concluir que las presunciones de hecho deben diferenciarse de las presunciones legales. Por ello, el ámbito de aplicación de las primeras no se encuentra en el $\ 292$, sino en el $\ 286$ inc. $1^{\circ}$ $\mathrm{ZPO}$, que establece el principio de libre valoración de la prueba.

De esta forma, resulta necesario renunciar al empleo de las presunciones de hecho como reglas de alteración de la distribución de la carga de la prueba, en el sentido empleado usualmente por la jurisprudencia. A causa de su falta de fundamento legal, una comprensión de las presunciones judiciales como reglas de alteración de la carga objetiva de la prueba deriva necesariamente en un abuso por parte de los órganos jurisdiccionales.

Las presunciones de hecho encuentran su fundamento en la utilización de reglas de la experiencia humana. Gracias a esta puede el juez en el caso concreto, por medio del empleo de una presunción de hecho, establecer como correctas si las conclusiones derivadas de un hecho cuya existencia se presume. ${ }^{419}$ Como las presunciones de hecho encuentran su fundamento en la experiencia general aplicada a un caso concreto, corresponden estas a una prueba indirecta o mediata.

La existencia de una presunción de hecho de menor grado resulta superflua atendida su pertenencia al ámbito de la prueba de indicios. Atendido lo anterior, el ámbito de aplicación de la prueba prima facie se limita a casos en los cuales la regla de la experiencia resulta por sí sola adecuada para que el juez tenga por acreditado un hecho controvertido.

Las presunciones de hecho, tal como la prueba prima facie, tienen su origen en máximas de la experiencia que permiten al juez alcanzar la plena prueba de la existencia de un hecho controvertido.

Cuando el juez alcanza el estándar de prueba suficiente para acreditar la existencia de un hecho controvertido por medio de la aplicación de máximas de la experiencia, no se verán influidas las reglas objetivas de carga de la prueba. ${ }^{420} \mathrm{La}$

\footnotetext{
418 LAUMEN en BAUMGÄrTEL et al. (2009), \14, pár. 10.

419 También en este sentido: ALLNER (1993), p. 65.

${ }^{420}$ También en este sentido: RosENBERG (1965), p. 187.
} 
legitimidad de las máximas de la experiencia para acreditar la existencia de un hecho se basa en su tipicidad.

El lugar que las presunciones de hecho ocupan en el ordenamiento jurídico corresponde al de una categoría con efectos paralelos al de la prueba prima facie, diferenciándose de esta en el tema sobre el que una y otra recaen. Mientras la prueba prima facie se emplea para la constatación de la causalidad y la culpabilidad, es elemento de la presunción judicial la averiguación de hechos distintos.

Como las presunciones legales y la prueba prima facie, el empleo de presunciones de hecho conduce a una simplificación de la actividad probatoria. Por medio de esta se posibilita la prueba de un elemento típico contenido en una disposición mediante la prueba exclusiva del hecho que fundamenta la presunción, no siendo necesaria la acreditación directa del hecho cuya existencia se busca probar. $^{421}$

Según su pertenencia al campo de la valoración de la prueba, la refutación se efectúa por medio de la contraprueba.

En contraposición a lo expresado por un sector de la doctrina ${ }^{422}$ no resulta necesario prescindir de la aplicación de esta institución, sino simplemente diferenciarla de instrumentos aparentemente similares, limitando asimismo sus efectos sin exceder las competencias exclusivas del legislador.

421 También en este sentido: AlLner (1993), p. 56; MK, PrütTing (2013), \ 292, pár. 28. 422 MK, PrÜtTiNG (2013), \292, pár. 28; WALTER (1979), p. 214; ZÖLLER, GREGER (2010), \ 284 pár. 33; MUSIELAK (2010), p. 566; (2012b), pár. 480. 


\section{BIBLIOGRAFÍA}

* Allner, Uwe (1993): Die tatsächliche Vermutung mit besonderer Berücksicbtigung der GEMAVermutung. Centaurus-Verlagsgesellschaft, Pfaffenweiler.

* AnZIger, Heribert M. (2006): Anscheinsbeweis und tatsächliche Vermutung im Ertragsteuerrecht. C.H.Beck, Baden-Baden.

* Baumbach, Adolf (2012): Zivilprozessordnung. Tomo I, 70. Ed., C.H.Beck, München.

* Baumgärtel, Gottfried (1990): "Die Bedeutung der. Sog. tatsächlichen Vermutung“ im Zivilprozeß”, en: GOTTARD, Peter / PRÜTTING, Hanns. Festschrift für Karl Heinz Schwab, C.H.Beck, München.

* Baumgärtel, Gottfried / Laumen, Hans-Willi / Prütting, Hanns (2009): (Editado por) Handbuch der Beweislast. Ed. Carl Heymanns, München.

* Bruns, Rudolf (1979): Zivilprozessrecht. 2. Auflage, Ed. Franz Vahlen, München.

* DÄnzer, Otto (1914): Die tatsächliche Vermutung: ein Beitrag zur Lebre vom Beweis im Zivilprozeß. Bensheimer, Mannheim.

* Grunsky, Wolfgang (2008): Zivilprozessrecht. 13. Ed, Carl Heymanns, München.

* Hainmüller, Dietmar (1986): Der Anscheinsbeweis und die Fahrlässigkeitstat im beutigen deutschen Schadensersatzproze $\beta$. Möhr Siebeck, Tübingen.

* Heinrich, Christian (1996): Die Beweislast bei Rechtsgeschäften. Heymann, Köln; Berlin; Bonn; München.

* Holzhammer, Richard (1986): "Die Einfache Vermutung in Zivilprozeß”, en Festschrift für Winfried Kralik zum 65. Geburtstag. Manzsche Verlag, Viena.

* Jauernig, Othmar; HESS, Burkhard (2011): Zivilprozessrecht. 30. Ed., C.H. Beck, München.

* KrÜger, Wolfgang; Rauscher, Thomas (2013): (Editado por) Münchener Kommentar zur ZPO. 4. Ed., C.H.Beck, München, citado como MK / nombre del encargado de la sección.

* LEPA, Manfred (1992): "Beweiserleichterungen im Haftplichtrecht", en NVZ.

* LÜKE, Wolfgang (2011): Zivilprozessrecht. 10. Ed., C.H. Beck, München.

* Musielak, Hans-Joachim (2010): Die sog. tatsächliche Vermutung. JA 8-9.

(2012a): (Editado por) Kommentar zur Zivilprozessordnung mit Gerichtsverfassungsgesetz: 9. Ed., Franz Vahlen, München, citado como Musielak / nombre del encargado de la sección.

(2012b): Grundkurs ZPO, 11. Ed., C.H. Beck, München.

(1975): Die Grundlagen der Beweislast im Zivilprozeß. de Gruyter, Berlin.

(2007): Examenskurs BGB: eine Darstellung ausgewählter Fragen aus dem Bürgerlichen Recht zur Examensvorbereitung mit einer eingehenden Lern- und Verständniskontrolle. C. H. Beck, München.

* Pohlmann, Petra (2011): Zivilprozessrecht. 2. Ed., C.H.Beck, München.

* Prütting, Hans (1983): Gegenwartsprobleme der Beweislast. Schriften des Instituts für Arbeits- und Wirtschaftsrecht der Universität zu Köln, C.H.Beck, München.

Münchener Kommentar zur ZPO, 4. Ed., C.H.Beck, München, 2013, citado como MK / nombre del encargado de la sección.

* Prütting, Hans; Gehrlein, Markus (2011): (Editado por). ZPO Kommentar. Luchterhand, 3. Ed., Köln, citado como: PGK / nombre del encargado de la sección.

* Rosenberg, Leo (1965): Die Beweislast, auf der Grundlage des Bürgerlichen Gesetzbuchs und der Zivilprozessordnung. 5. Ed., C. H. Beck, München.

* Rosenberg, Leo; SCHWAB, Karl Heinz; GotTward, Peter (2010): Zivilprozessrecht. 17. Ed., C.H. Beck, München.

* Saenger, Ingo (2013): (Editado por) Zivilprozessordnung, Handkommentar. 5. Ed., Nomos, Baden-Baden, citado como: Hk-ZPO / nombre del encargado de la sección. 
Correa - La presunción de hecho como figura jurídica en el derecho procesal civil alemán

* Schellhammer, Kurt (2007): Zivilprozess Gesetz-Praxis-Fälle. 12. Ed., C. F. Müller, Heidelberg.

* Schwab, Martin (2012): Zivilprozessrecht. 4. Ed., C. F. Müller, Heidelberg: München; Landsberg [entre otros.

* _ (2013) Erstgutachten zur Masterarbeit. Die tatsächliche Vermutung als Rechtsfigur des zivilprozessualen Beweisrechts, von Herrn Carlos Correa Robles. Inédito.

* STEIN, Friedrich; JonAS, Martin (2008): (editado por). Kommentar zur Zivilprozessordnung. Mohr Siebeck 22. Ed. Tübingen, citado como: SJK / nombre del encargado de la sección.

* Walter, Gerhard (1979): Freie Beweiswürdigung. Mohr Siebeck, Tübingen.

(1977): “Der Anwendungsbereich des Anscheinsbeweises",Zeitschrift für Zivilprozeß 90. Carl Heymanns Verlag KG, Köln, Berlin, Bonn, München.

* Wassermeyer, Heinz (1954 reimpresión 1995): Der prima facie Beweis und die benachbarten Erscheinungen. Aschendorffsche Verlagsbuchhandlung. Münster Westfalen.

* WieCZOREK, Bernhard / SCHÜTZE, Rolf A. (2012): (Editado por). Zivilprozeßordnung und Nebengesetze: Großkommentar de Gruyter (gran comentario práctico) 4. Ed., Tomo. 4, Berlin, New York, citado como: WSK / nombre del encargado de la sección.

* ZÖlLER, Richard (2010): (Editado por). Zivilprozessordnung Kommentar. 29. Ed, Editorial Dr. Otto Schmidt, Köln, citado como: Zöller / nombre del encargado de la sección. 